
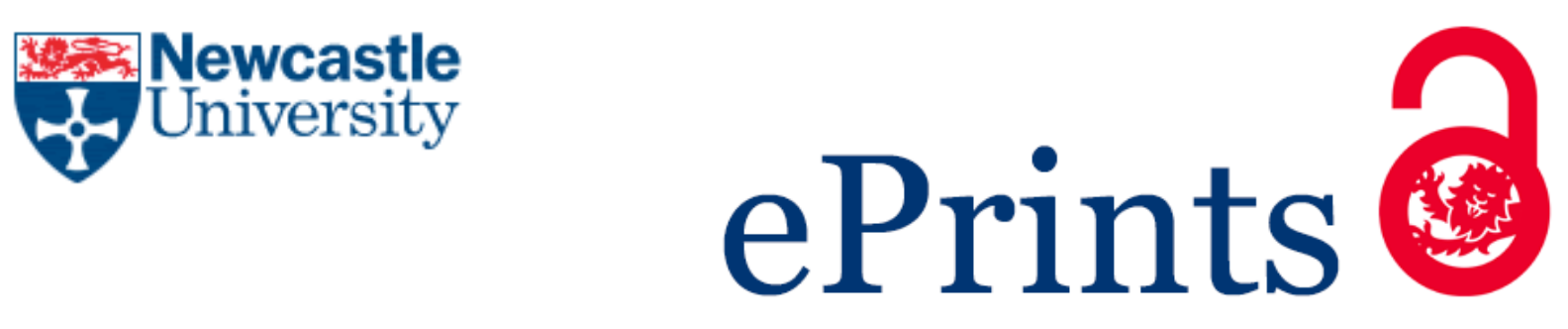

Shi C, Hu Z, Ringsberg J, Luo Y.

A nonlinear viscoelastic iceberg material model and its numerical validation. Proceedings of the Institution of Mechanical Engineers, Part M: Journal of

Engineering for the Maritime Environment 2017

DOI: https://doi.org/10.1177/1475090216680907

\title{
Copyright:
}

This is the authors' accepted manuscript of an article that was published in its final definitive form by Sage, 2017.

DOI link to article:

https://doi.org/10.1177/1475090216680907

Date deposited:

$03 / 02 / 2017$

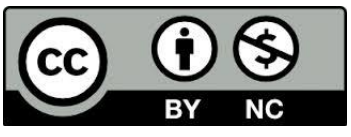

This work is licensed under a Creative Commons Attribution-NonCommercial 3.0 Unported License 


\section{A nonlinear viscoelastic iceberg material model and its numerical}

\section{validation}

Chu Shi ${ }^{1,2}$, Zhiqiang $\mathrm{Hu}^{1,3}$, Jonas Ringsberg ${ }^{4}, \mathrm{Yu} \mathrm{Luo}^{1}$

1. State Key Laboratory of Ocean Engineering, Shanghai Jiao Tong University, Shanghai, China

2. Collaborative Innovation Centre for Advanced Ship and Deep-Sea Exploration, Shanghai Jiao Tong University, Shanghai, China

3. School of Marine Science \& Technology, Newcastle University, Newcastle upon Tyne, NE1 7RU, UK

4. Department of Shipping and Marine Technology, Chalmers University of Technology, Gothenburg, Sweden

\section{Nomenclature}

\begin{tabular}{|c|c|c|c|}
\hline$\varepsilon^{e}$ & instantaneous elastic strain (-) & $\sigma^{d}$ & Cauchy stress on Kelvin unit $(\mathrm{Pa})$ \\
\hline$\varepsilon^{d}$ & delayed elastic strain (-) & $u_{i j}$ & deviatoric stress $(\mathrm{Pa})$ \\
\hline$\varepsilon^{v}$ & viscous strain (-) & $y_{0}, a_{0}, r_{0}$ & fitting parameters in Maxwell unit \\
\hline$\varepsilon^{c r}$ & crack strain (-) & $y_{1}, a_{1}, r_{1}$ & fitting parameters in Kelvin unit \\
\hline$\varepsilon^{c}$ & creep strain (-) & $\mathrm{c}$ & scale parameter \\
\hline $\bar{\varepsilon}^{c}$ & equivalent creep strain $\left(\mathrm{s}^{-1}\right)$ & $\delta_{i j}$ & delta function \\
\hline $\mathrm{E}_{1}$ & elastic stiffness of Kelvin unit (Pa) & $p$ & hydrostatic pressure ( $\mathrm{Pa})$ \\
\hline $\mathrm{E}_{2}$ & elastic stiffness of Maxwell unit (Pa) & $S / S_{1} / S_{2}$ & damage function (s) \\
\hline$E_{2 n}$ & $\mathrm{E}_{2}$ with damage effects $(\mathrm{Pa})$ & $S_{f}$ & failure criteria (s) \\
\hline$G_{n}$ & $\begin{array}{l}\text { shear modulus with damage effects } \\
\text { (Pa) }\end{array}$ & $b$ & $\begin{array}{l}\text { damage parameter for elastic/shear } \\
\text { modulus }\end{array}$ \\
\hline$\eta_{1}$ & $\begin{array}{l}\text { viscosity coefficient of in Kelvin unit } \\
(\mathrm{Pa} \cdot \mathrm{s})\end{array}$ & $q_{1} / q_{2} / q_{3}$ & $\begin{array}{l}\text { exponent parameters in damage } \\
\text { function }\end{array}$ \\
\hline$\eta_{2}$ & $\begin{array}{l}\text { viscosity coefficient of Maxwell unit } \\
(\mathrm{Pa} \cdot \mathrm{s})\end{array}$ & $\sigma_{0}$ & $\begin{array}{l}\text { reference stress in damage function } \\
(\mathrm{Pa})\end{array}$ \\
\hline$\sigma / \sigma_{i j}$ & Cauchy stress $(\mathrm{Pa})$ & $m$ & exponent parameter of Maxwell unit \\
\hline $\bar{\sigma}$ & equivalent stress (Pa) & $f\left(\dot{\varepsilon}^{v}\right)$ & $\begin{array}{l}\text { strain rate function in Kelvin/Maxwell } \\
\text { unit }\end{array}$ \\
\hline
\end{tabular}

\section{Abstract}

This paper proposes a nonlinear viscoelastic iceberg material model. A nonlinear Burgers' model in which Kelvin and Maxwell units are strain rate- and stress-dependent is adopted for the iceberg material. The strain rate effect is considered in this model based on the experimental results. The stress of the iceberg model grows linearly (in log form) with increasing strain rate before reaching the transition strain rate, after which the stress remains rather constant. A damage function that reflects microstructure changes and severe fractures in ice is adopted as the failure criterion. The iceberg model 
is implemented using implicit integration Crank-Nicolson method and is incorporated in the commercial software LS-DYNA by a user-defined material. Laboratory-scale experiments, creep experiments and constant strain rate experiments, and reality-scale experiment, iceberg-rigid steel plate collisions, are simulated to validate the proposed iceberg material model. Simulated time-strain curves are compared with the results of creep experiments. In the constant strain rate experiments, the strain-stress curves for brittle and ductile failure and ultimate triaxial strength of the ice model are analysed. Area-pressure curves and contact force-displacement relations are investigated for different impact speeds in icebergsteel plate collisions. Contact force is also studied in view of the kinetic energy of icebergs. The numerical results show that the proposed iceberg material model yields reasonably good results.

Key words: nonlinear viscoelasticity, iceberg material, numerical validation, laboratory scale, reality scale

\section{Introduction}

Human activity in the Arctic area has increased rapidly in recent years due to increases in the exploitation of oil resources, economical sea routes and tourist operations. The increased number of vessels and marine structures increases the potential for collisions between small icebergs (bergy bits) and ships and offshore structures. Large icebergs can be detected by radar, and collisions can be avoided through iceberg management in advance. Nevertheless, small icebergs cannot be easily detected by radar or by pilots, particularly in mist and in pack ice. From 1985 to 2005, there were an average of 2.3 ship-iceberg collision accidents each year in the Arctic area ${ }^{1}$. Therefore, it is essential to study iceberg collision mechanisms and predict the contact force for the safety purposes of marine structures activated in the Arctic area.

Several iceberg impact experiments2-5 have been conducted to determine the collision force directly. 
In these tests, small icebergs were towed to an impact testing facility, where steel plates or bows of icebreaker are equipped with sensors. The contact force, pressure distribution and kinetic energy of an iceberg could be measured. Based on these, empirical formulas of ice impact force, such as areapressure curves, were proposed. Some of these empirical formulas are adopted by classification societies' ice rules. Nevertheless, these empirical data are far from sufficient to estimate ice load accurately because they do not illustrate the complex mechanism of the ship-iceberg impact and are also limited to certain regions and ship parts.

Many strength experiments have been conducted with ice models to study the mechanical properties of ice material. For example, Frederking and Hausler ${ }^{6}$ measured the flexural strength of sea ice, Iliescu and Schulson ${ }^{7}$ measured the biaxial compressive strength of freshwater ice, and Polach and Ehlers ${ }^{8}$ conducted tensile, compressive and bending experiments with model scale ice. These experiments showed that the mechanical properties of ice material can be influenced by many factors, which can either be intrinsic (e.g., temperature, salinity, density, ice type, crystal size and orientation) or test conditions (e.g., rate of loading, confinement conditions, loading direction, sample size, stiffness of the test machine and sample preparation techniques) ${ }^{9}$. In the scenario of ship-iceberg collision, the iceberg is in a triaxial stress condition at the contact area ${ }^{10}$. Therefore, data from triaxial compressive experiments of iceberg ice are highly recommended for the study of ship-iceberg impact. Gagnon and Gammon $^{11,12}$ reported the results of triaxial compression, flexural strength and impact tests on iceberg ice. Jones et al. ${ }^{13}$ conducted uniaxial compressive tests of iceberg ice. Muggeridge and Jordaan ${ }^{14}$ discussed the microstructure changes in the contact area of iceberg obtained from full-scale icebergimpact experiments in detail. Polach and Ehlers ${ }^{15}$ studied the scalability of model ice and conducted a qualitative assessment on the differences between model-scale ice and sea ice. 
The numerical simulation method is another important way to study structure crashworthiness in the ship-iceberg collision problem; examples include the smoothed particle hydrodynamics (SPH) method used by Das and Ehlers ${ }^{16}$ and the discrete element method used by Shunying Ji et al. ${ }^{17}$. The finite element method is one of the prevailing tools. An accurate constitutive material model of ice is of great importance for finite element simulations of the ship-iceberg collision process. Several constitutive models of ice material have been proposed based on mechanical experiments. Nevertheless, the ice material model is not well established due to many factors affecting ice behaviours. Liu Z et al. ${ }^{10}$ proposed an elastic-perfect-plastic ice model that had an empirical failure criteria and 'TsaiWu' yield surface. Gagnon ${ }^{18}$ presented a 'crushable foam' ice model which behaved as elastic-linearhardening material and simulated a tanker impact with a bergy bit ${ }^{19}$. Derradji-Aouat ${ }^{20,21}$ established two ice models for low strain rate $\left(<10^{-3} \mathrm{~s}^{-1}\right)$ and high strain rate. Schapery ${ }^{22}$ proposed a nonlinear

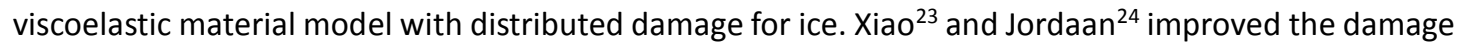
function of this model, which can reflect the influence of confining pressure on the ice damage model. In these ice material models, the material parameters are typically determined from ice experiments. Ehlers $^{25,26}$ presented a particle swarm optimization algorithm to obtain ice material parameters and applied it to parameter decisions in a simulation of four-point bending experiments of sea ice.

In this paper, an improved nonlinear viscoelastic iceberg material considering transition strain rate effects and failure criteria is proposed based on the research of Jordaan et al. ${ }^{27}$. The exponential damage evolution law is established to reflect the influence of strain rate on the compressive strength of ice under triaxial stress state. An empirical failure criterion based on the damage function is proposed to describe the accumulation of microstructure change and large fracture failure in icebergs. The model proposed in this paper is limited to iceberg ice, which can be considered an isotropic material ${ }^{9}$ and is 
focused on the mechanical behaviour of iceberg ice. The temperature effects and probability of ice physical properties are not considered. This 3D model of ice is numerically implemented by implicit integration Crank-Nicolson method and incorporated into the LS-DYNA finite element code using a userdefined subroutine. The validation is performed using two laboratory scale experiments-creep experiments and constant strain rate experiments conducted by Jordaan ${ }^{24}$ and Gagnon and Gammon ${ }^{11}$, respectively-and one reality experiment-collision between iceberg and rigid steel plate. Simulated results correspond well with experimental results. The model regards iceberg as a whole and neglects micro effects during the experiments. It is validated by global experimental results, such as areapressure curves and contact force-displacement curves, and is limited to engineering applications.

\section{Presentation of nonlinear viscoelastic material model of iceberg}

Polycrystalline ice behaves as a brittle, nonlinear viscoelastic material under a wide range of conditions of engineering interest ${ }^{1,22}$. In this section, a 3D nonlinear viscoelastic iceberg material model is presented. Icebergs contain defects, and accumulations of microcracks and fracture failure appear in ship-iceberg collisions. Therefore, damage evolution and failure criteria are considered in this material model. Implicit algorithm is applied to numerical implementation. One-element numerical tests are conducted to verify the correctness of the numerical implementation process.

\subsection{Nonlinear viscoelastic material model for iceberg ice}

In nature, ice exists at high homologous temperature $\left(T_{h}>0.8\right)$ and is prone to creep under any level of stress ${ }^{24}$. Burgers' model, consisting of a Maxwell unit and a Kelvin unit, is typically used to describe viscoelastic materials, such as rock, cement and ice ${ }^{23}$. Figure 1 shows Burgers' model. The total strain of 
ice equals the sum of the instantaneous elastic strain $\left(\varepsilon^{e}\right)$, delayed elastic strain $\left(\varepsilon^{d}\right)$, viscous strain $\left(\varepsilon^{v}\right)$ and strain $\left(\varepsilon^{c r}\right)$ induced by cracking ${ }^{28}$. The first three components can be described by the spring $\left(E_{2}\right)$ in Maxwell unit, the dashpots $\left(\eta_{2}\right)$ in Maxwell unit and the Kelvin unit $\left(E_{1}\right.$ and $\left.\eta_{1}\right)$, respectively. The fourth part of the ice strain can be considered using the damage evolution law and be coupled in the first three components.

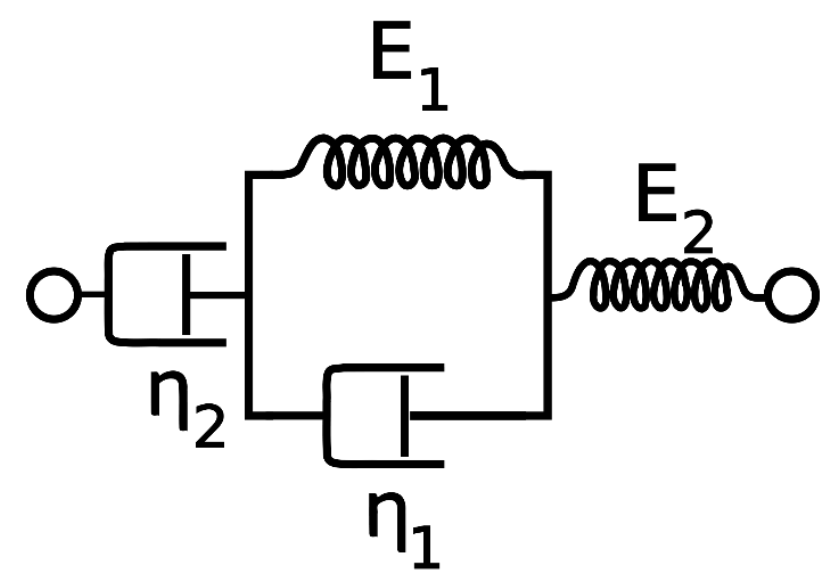

Figure 1 Burgers' model consisting of a Maxwell unit $\left(E_{2}, \eta_{2}\right)$ and Kelvin unit $\left(E_{1}, \eta_{1}\right)$.

For the uniaxial stress state, the instantaneous strain $\left(\varepsilon^{e}\right)$, delayed elastic strain rate $\left(\dot{\varepsilon}^{d}\right)$ and viscous strain rate $\left(\dot{\varepsilon}^{v}\right)$ are given by Equations (1) to (3), respectively.

$$
\begin{aligned}
& \varepsilon^{e}=\frac{\sigma}{\mathrm{E}_{2}} \\
& \dot{\varepsilon}^{d}=\frac{\sigma^{d}}{\eta_{1}} \\
& \dot{\varepsilon^{v}}=\frac{\sigma}{\eta_{2}}
\end{aligned}
$$

where $\sigma^{d}$ equals the stress applied to the dashpot of the Kelvin unit, shown in Equation (4). $\varepsilon^{d}$ represents the accumulation of the delayed elastic strain, as shown in Equation (5).

$$
\begin{gathered}
\sigma^{d}=\sigma-\varepsilon^{d} \mathrm{E}_{1} \\
\varepsilon^{d}=\int_{0}^{t} \dot{\varepsilon}^{d} d t
\end{gathered}
$$

A single linear Burgers' model typically cannot describe ice behaviour accurately. Serial Kelvin units 
or parallel Maxwell units can be adopted to fit complex material behaviour. Nevertheless, it is difficult to determine each constant parameter of every Kelvin/Maxwell unit, particularly when many Kelvin/Maxwell units are used. Moreover, the physical meaning of each Kelvin/Maxwell unit is not clear. Application of the nonlinear component of Burgers' model is another way to describe complex materials, such as asphalt, rock and metal. The term 'nonlinear' means that the parameters of Kelvin/Maxwell units $\left(E_{1}, \eta_{1}, E_{2}, \eta_{2}\right)$ are functions of stress, time or temperature instead of constant values. Jordaan et al. ${ }^{24,27}$ proposed a nonlinear viscoelastic ice model in which the dashpot of the Maxwell unit depends on stress, as shown in Equation (6). This model fits well with the results of the creep experiments at relatively low and moderate strain rates. Upon the transition strain rate, approximately $2 \times 10^{-3} \mathrm{~s}^{-1}$, the ice strength from the experiments remains constant or decreases slightly ${ }^{11,29}$. However, the model of Jordaan et al. cannot capture this behaviour of ice because the stress from the Jordaan model continues to increase with increasing strain rate, as shown in Figure 2.

$$
m \log \sigma=\log \eta_{2}+\log \dot{\varepsilon}^{v}
$$

where $m$ is a constant parameter.

An improved nonlinear viscoelastic Burgers model considering transition strain rate effects is established. When the strain rate is smaller than the transition rate, the material model is the same as that of Jordaan et al. ${ }^{27}$. When the strain rate is larger than the transition rate, the formula of a nonlinear Maxwell unit, shown in Equation (7) and illustrated in Figure 2, is adopted. At the same time, the linear Kelvin unit is translated into a stress-dependent component, as shown in Equation (8). 


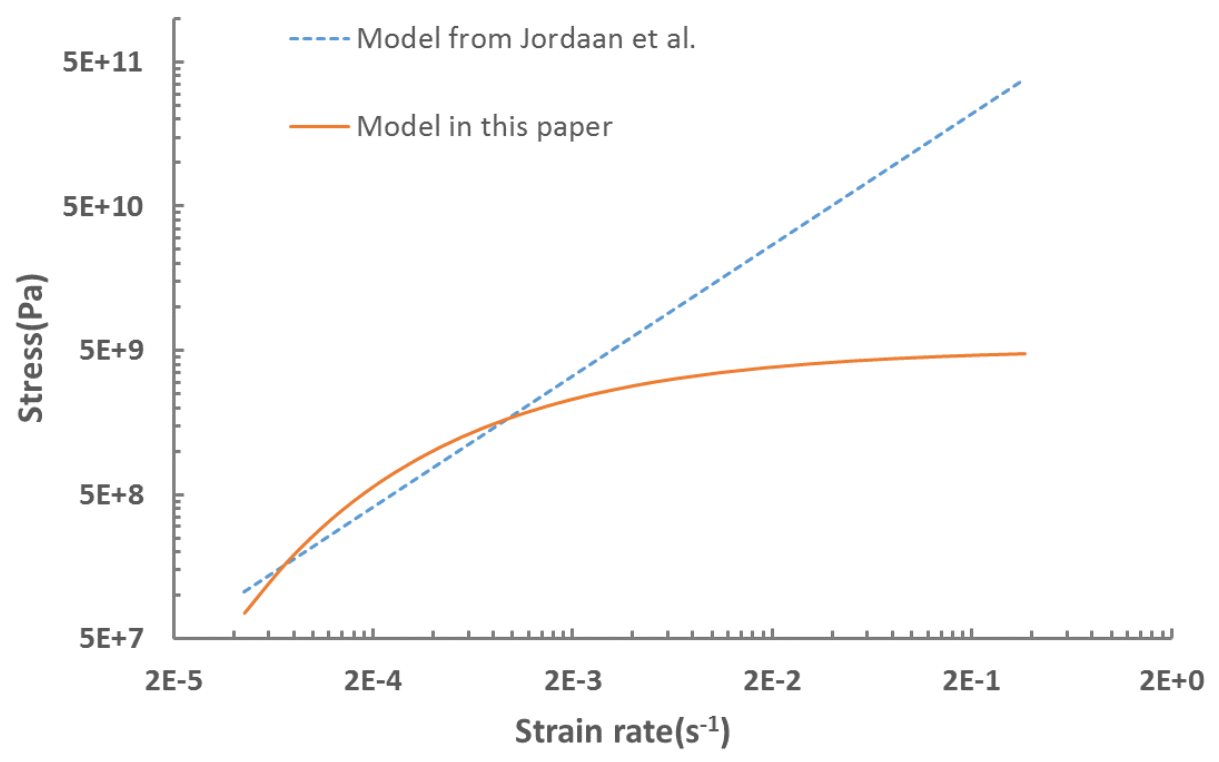

Figure 2 Comparison of the nonlinear dashpot in Maxwell between the material model proposed by Jordaan and the material model in this paper.

$$
\begin{aligned}
& \log \sigma=y_{0}+a_{0} e^{r_{0} \log \varepsilon^{v}}=y_{0}+a_{0}\left(\dot{\varepsilon}^{v}\right)^{r_{0}} \\
& \log \sigma^{d}=y_{1}+a_{1} e^{r_{1} \log \varepsilon^{d}}=y_{1}+a_{1}\left(\dot{\varepsilon}^{d}\right)^{r_{1}}
\end{aligned}
$$

where $y_{0}, y_{1}, a_{0}, a_{1}, r_{0}$ and $r_{1}$ are constant parameters.

When the strain rate is larger than the transition rate, the stress can be expressed by $\log \sigma_{\exp }=$ $\frac{y_{0}+a_{0}\left(\dot{\varepsilon}^{v}\right)^{r_{0}}}{m\left(\log \eta_{2}+\log \varepsilon^{v}\right)} \log \sigma_{\text {linear }}$, where $\sigma_{\text {exp }}$ is the stress in Equation (7), and $\sigma_{\text {linear }}$ is the stress in Equation (6). Therefore, the two formulas can be expressed in a single expression, Equation (9). This is the nonlinear dashpot of the Maxwell unit applied in this paper. The expression of the nonlinear dashpot of the Kelvin unit has the same form. The fitting parameters in the Maxwell unit and Kelvin unit are obtained by fitting the ultimate strength of ice in triaxial compressive experiments conducted at different strain rates. There are two aspects of the scale effect in these parameters. First, experimental data reflect the behaviour of the entire ice sample, and there is a scale effect between the behaviour of an entire sample and that of a single ice element. Second, because the parameters in the Kelvin unit 
and Maxwell unit are fitted from experimental data that are supposed to be reflected by the entire Burgers model, there is a scale effect between the Maxwell/Kelvin unit and the Burgers model. These two scale effects are considered to be reflected by parameter c, shown in Equation (10). The value of $c$ is determined based on trial-and-error simulations.

$$
\begin{aligned}
& \sigma=\frac{\eta_{2}}{\sigma^{m f\left(\dot{\varepsilon}^{v}\right)-1}} \dot{\varepsilon}^{v} \\
& \text { where } f\left(\dot{\varepsilon}^{v}\right)=\left\{\begin{array}{cl}
1 & \dot{\varepsilon}^{v} \leq \dot{\varepsilon_{t}} \\
c \frac{\log \eta_{2}+\log \varepsilon^{v}}{m\left(y_{0}+a_{0}\left(\dot{\varepsilon}^{v}\right)^{r_{0}}\right)} & \dot{\varepsilon}^{v}>\dot{\varepsilon_{t}}
\end{array}\right.
\end{aligned}
$$

The aforementioned model is obtained based on creep experiments (constant stress) and is available only for a constant load. When considering a varying load situation, such as a ship-iceberg collision, strain-rigidification theory is adopted to account for the influence of prior creep on the following creep. First, the stress history is subdivided by the number of time steps, which is sufficiently small, and the stress in each time step can be regarded as constant. When the stress changes from $\sigma_{3}$ to $\sigma_{4}$, as shown in Figure 3, the creep strain (point A) remains unchanged (termed strain-rigidification) and is translated into a new time-creep strain curve that corresponds to a new stress $\left(\sigma_{4}\right)$ state. The pseudo time $(\bar{t})$, corresponding to the creep strain $\left(A^{\prime}\right)$ in the new curve, is then obtained and will be used in the following creep strain calculation. 

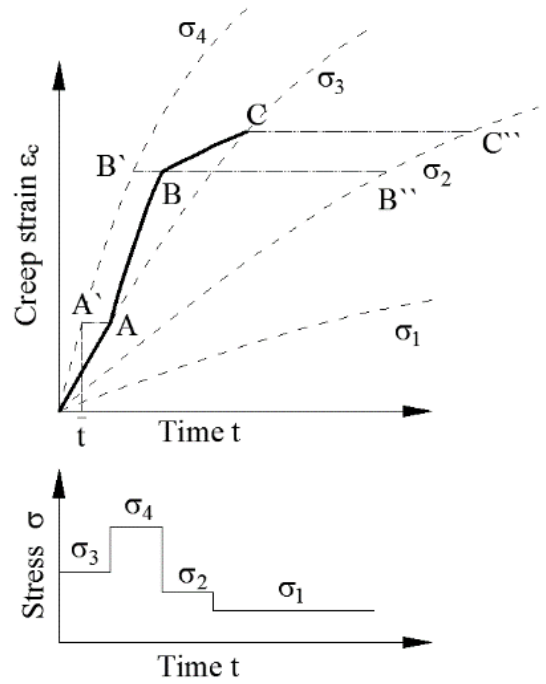

Figure 3 Illustration of strain-rigidification theory.

The pseudo time in each time step is calculated by solving the creep strain-time formulation, shown in Equation (11). The Newton iteration method is applied to solve this formulation. This method is convergent when $t$ is in the range from 0 to $\infty$. Therefore, the initial value of $t$ in the iterative formula is set to zero.

$$
\varepsilon^{c}=\left[\frac{t}{\eta_{2}}+\frac{1}{E_{1}}\left(1-e^{-\frac{E_{1} t}{\eta_{1}}}\right)\right] \sigma
$$

For the multi-axial stress state, the elastic response of the iceberg material is assumed to be isotropic; therefore, the elastic strain components $\varepsilon_{i j}^{e}$ can be expressed as

$$
\varepsilon_{i j}^{e}=-\frac{v}{E_{2}} \sigma_{k k} \delta_{i j}+\frac{1+v}{E_{2}} \sigma_{i j}
$$

where $v$ is Poisson's ratio and $\delta_{i j}$ is the delta function.

The components of creep strain, similar to plastic strain, are assumed to be parallel with deviatoric stress. Therefore, they are in proportion to the components of deviatoric stress, as shown in Equation (13).

$$
\dot{\varepsilon}_{i j}^{c}=\frac{3}{2} \frac{\dot{\varepsilon}^{c}}{\bar{\sigma}} u_{i j}
$$

where $u_{i j}$ are the components of deviatoric stress and $\dot{\bar{\varepsilon}}^{c}, \bar{\sigma}$ are the equivalent creep strain rate 
and equivalent stress, respectively.

$$
\begin{aligned}
\dot{\bar{\varepsilon}}^{c} & =\frac{\sqrt{\frac{2}{3} d \varepsilon_{i j}^{c} d \varepsilon_{i j}^{c}}}{d t} \\
\bar{\sigma} & =\sqrt{\frac{3}{2} u_{i j} u_{i j}}
\end{aligned}
$$

\subsection{Damage evolution and failure criteria}

The model described above is for intact iceberg material only. The influence of damage on ice behaviour will be discussed in this section. Ice grown in the field includes many defects, such as pores, flaws, brine and cracks. At high loading rates, these defects will intervene to cause fracture to occur at relatively low stresses24. Consequently, the strength of nature ice, particularly for iceberg ice and multiyear ice, is relatively weak and scattered. Therefore, it is critical to consider the effects of damage in the ice model.

Schapery ${ }^{22}$ developed a constitutive theory for a nonlinear viscoelastic material with uniformly distributed microcracks. Harper ${ }^{30}$ applied this model to ice and found it to be consistent with the behaviour of ice under constant load. Based on Schapery's ${ }^{22}$ theory, Singh ${ }^{31}$ developed a single scalar variable damage model that reflected the influence of loading stress on microcrack behaviour in ice. During a ship-iceberg collision, not only microcracks but also other possible microstructure changes, such as recrystallization and pressure melting, may appear in ice. The generation and evolution of the damage depend on the confining pressure, strain rate and loading stress. Xiao ${ }^{23}$ and Jordaan ${ }^{24}$ improved the damage function by considering the influence of the confining pressure on damage, as shown in Equation (16). The state variable $S_{1}$ is mainly related to microcracks under low confining pressure. $S_{2}$ is mainly associated with pressure melting and recrystallization under high confining pressure ${ }^{23,24}$. The damage function (16) is adopted in this paper. 


$$
\mathrm{S}=S_{1}+S_{2}=\int_{0}^{t}\left(f_{1}(p)\left(\frac{\sigma}{\sigma_{0}}\right)^{q_{1}}+f_{2}(p)\left(\frac{\sigma}{\sigma_{0}}\right)^{q_{2}}\right) d t
$$

where

$f_{1}(p)=\left\{\begin{array}{cc}0.7\left(1-\frac{p}{50}\right)^{2} & p<50 M P a \\ 0 & p \geq 50 M P a\end{array}\right.$

$f_{2}(p)=0.12\left(\frac{p}{50}\right)^{q_{3}}$

$q_{1} / q_{2} / q_{3}$ are constant parameters and $\sigma_{0}$ is the reference stress.

The reduction of ice elastic properties caused by damage generation and evolution can be expressed by Equations (17) and (18), respectively ${ }^{32}$.

$$
\begin{gathered}
\frac{E_{2 n}}{E_{2}}=(1+b S)^{-1} \\
\frac{G_{n}}{G}=(1+b S)^{-1}
\end{gathered}
$$

where $E_{2 n}$ is the elastic modulus of ice material considering damage effects, $G_{n}$ is the shear modulus of ice material considering damage effects, and $b$ is a constant parameter.

In ice under loading, micro-scale damage, such as microcracks, recrystallization and pressure melting, continues to progress. Large fracture appears, and the ice sample is regarded as losing stress capability when the accumulation of microscale damage reaches a critical value. Based on this hypothesis, damage parameter $\mathrm{S}$ (expressed in Equation (16)) can be treated as a simplified failure criterion. When $\mathrm{S}$ in an ice element is greater than the critical damage value $S_{f}\left(\mathrm{~S}>S_{f}\right)$, erosion is activated, and this element is deleted. When the ice element is to be deleted, the damage value is large and the bearing capability is weak. Therefore, the sudden deletion of ice element will not lead to large deviation of contact fore. Nevertheless, erosion method devotes to the fluctuation of interface pressure and this is considered as acceptable in this paper. As stated earlier, the model focuses on global responses of iceberg. Therefore, damage parameter $\mathrm{S}$ reflects the influence of defects on global mechanical behavior instead of local effects. 


\subsection{Numerical implementation and one-element verification}

Based on trial numerical simulations of creep experiments of ice, the implicit integration is more stable than the explicit incremental scheme, particularly for the unloading process. Therefore, the implicit integration has been applied to the implementation of the 3D iceberg material model. Figure 4 shows the framework of the main program. The notation meanings and detailed derivation are shown in the APPENDIX.

One-element numerical tests have been conducted to verify the correctness of the implementation process. Eight node constant stress solid element (element formulation=1 in LS-DYNA) is used. The bottom of the element is completely fixed, and the top four nodes only have freedom in x-direction. Appropriate around loads (in y-and z-direction) are applied to the top four nodes to make this element in one-dimensional stress state. The nonlinear viscoelastic ice model is degenerated into linear viscoelasticity by setting $m=f\left(\dot{\varepsilon}^{v}\right)=1$ in Equation (9). The damage effects are also not included by setting $b=0$ in Equations (17) and (18). Therefore, the numerical results can be compared with linear viscoelastic theory results. As ship-ice collision process includes loading and unloading; three types of loading states are applied to this element-constant loading, increasing loading and unloading. Comparison of the numerical results and theoretical results is shown in Figure 5 . The ice model shows good consistency with the theoretical results, indicating that the implementation of this model is correct. 


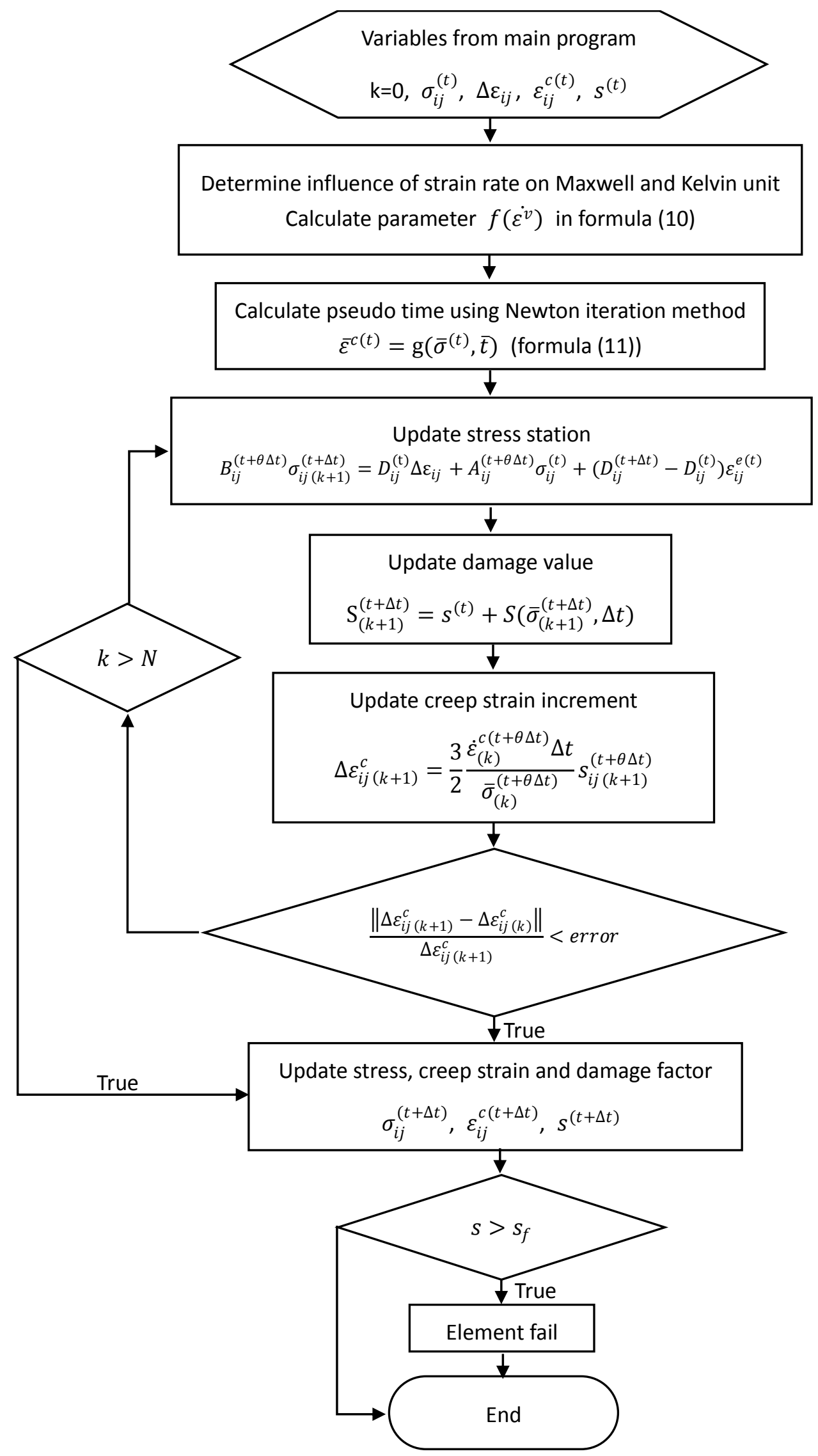

Figure 4 Flowchart of implementation program. The notation meanings are defined in the Appendix. 


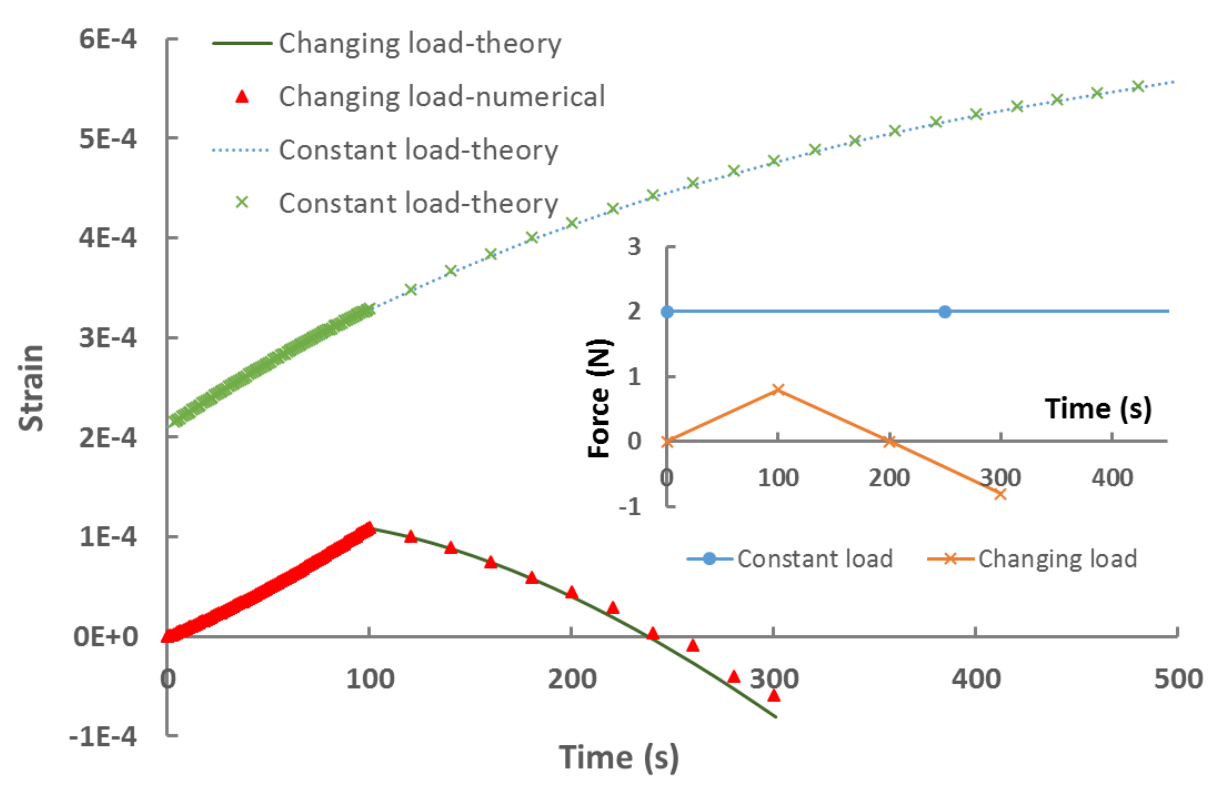

Figure 5 Comparison between the one-element simulation results and theoretical results for the

one-dimensional loading condition.

\section{Numerical simulation and discussion of three cases}

To validate the iceberg material model proposed in this paper, creep experiments, constant strain rate experiments and collision between spherical iceberg and rigid steel plate are simulated through numerical simulation technology and LS_DYNA code ${ }^{33}$. For the two laboratory-scale simulation experiments, simulated results, such as the curves of strain in time series, curves of strain-stress and curves of ultimate strength, are compared with the corresponding experimental results. For reality-scale iceberg-plate collisions, curves of pressure-area are compared with those by design codes. The iceberg behaviour reflected by the curves of contact force in time series during the collision process are also analysed.

\subsection{Creep experiments of ice under triaxial compressive conditions}

The creep experiment is one of the prevailing experimental methods to study the mechanical behaviour of ice material. In a ship-iceberg collision, the major contact force is translated through 
several small contact areas in the iceberg, which are called 'high-pressure zones'. Ice in these areas is in the triaxial stress state. $\mathrm{XiaO}^{23}$ and Jordaan ${ }^{24}$ conducted a series of creep experiments of granular ice to study the behaviour of ice in high-pressure zones. The loading station of the cylinder ice specimen is shown in Figure 6. Laboratory-prepared granular ice with the same grain structure as iceberg ice was used, and the seeds to make ice specimens were 2.00 to $3.36 \mathrm{~mm}$ in length. The temperature of the ice was $-10^{\circ} \mathrm{C}$. The diameter and length of the ice specimen were 70 and $175 \mathrm{~mm}$, respectively. It should be noted that the possible defects between iceberg ice and laboratory-made ice are different. The creep experiments of iceberg ice are needed in the future.

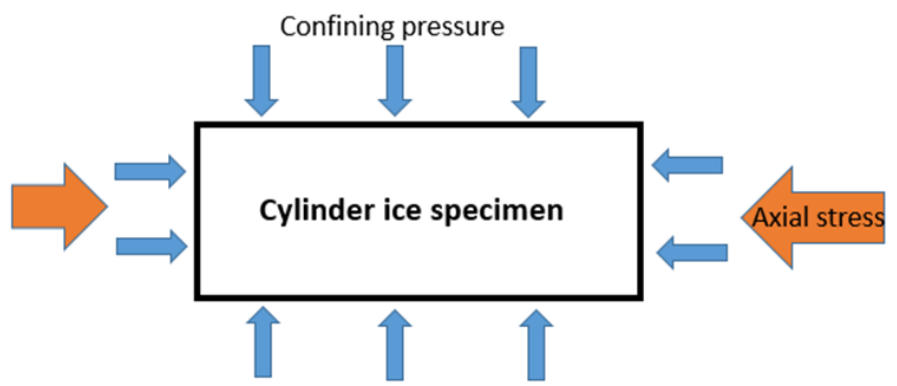

Figure 6 Stress station of the cylinder ice specimen. The confining pressure remains constant (10 $\mathrm{MPa})$, and the axial stress varies from 5 to $10 \mathrm{MPa}$.

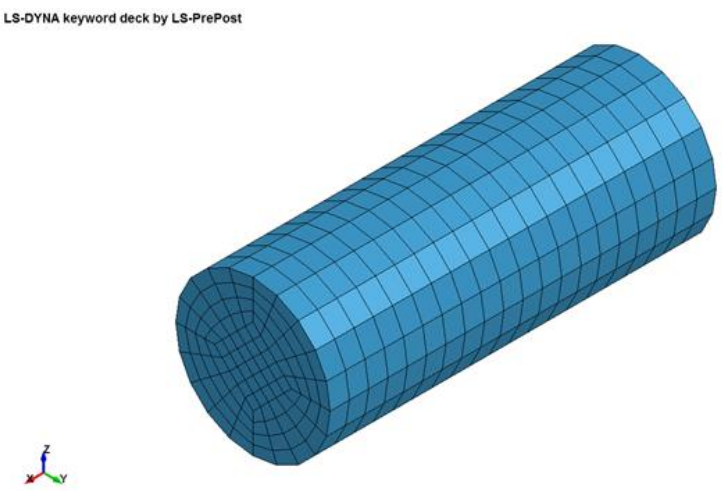

Figure 7 Illustration of the numerical model of the cylindrical ice specimen.

Three typical creep experiments conducted by $\mathrm{XiaO}^{23}$ and Jordaan ${ }^{24}$ are simulated using the ice model 
proposed in this paper. In these three experiments, the confining pressure is $10 \mathrm{MPa}$, and the axial stress is 5, 8 and $10 \mathrm{MPa}$. The simulation model is shown in Figure 7. Convergence analyses of element size are carried out, and three element sizes, $2 \mathrm{~mm} \times 4 \mathrm{~mm} \times 4 \mathrm{~mm}, 5 \mathrm{~mm} \times 8 \mathrm{~mm} \times 8 \mathrm{~mm}$ and $8 \mathrm{~mm} \times 18 \mathrm{~mm} \times 18$ $\mathrm{mm}$, are tested. These three element sizes yield similar simulation results, meaning that this simulation is not sensitive to the element size. This lack of sensitivity may be because the cylindrical ice model and cubic element are regular shapes, and the deformation in the creep experiments is small. Considering the computational expense and the precision of damage distribution in the ice model, a mesh size of 5 $\mathrm{mm} \times 8 \mathrm{~mm} \times 8 \mathrm{~mm}$ is adopted. The nodes at the bottom of the cylinder specimen are fixed. Sum of the axial stress and confining pressure is applied to the nodes at the top of the ice specimen, and the confining pressure is applied to segments at the cylinder surface of the ice specimen. The loads are applied at the beginning and keep constant through the simulation process. The simulation is completed in LS-DYNA code, and the explicit integration method is adopted. In this method, the calculation time equals the actual duration of the creep experiments (20 s to $200 \mathrm{~s}$ ), which is relatively long compared to the calculation time of other problems, such as ship-ice collisions and melt forming, with typical durations of $0.01 \mathrm{~s}$ to $1 \mathrm{~s}$. The mass scaling method m, $^{35}$ is adopted to increase the calculation step size and reduce the computational expense. The mass scaling factor is set to 1,000 , and kinetic energy is controlled to less than $0.5 \%$ of the internal energy.

The values of the material parameters in the ice model, shown in Table 1, are obtained by fitting the time-axial strain curve of creep test conducted at axial stress of $7 \mathrm{MPa}$. In the creep experiment simulations conducted in this section, the ice model is degenerated to the model proposed by Jordaan et al. ${ }^{27}$ for two reasons. First, loading rates of creep tests are smaller than the transition rate, and $f\left(\dot{\varepsilon}^{v}\right)$ $=1$, which means that the expressions of Burgers' model are the same as those of Jordaan's model. 
Second, failure criterion is not activated because no critical fracture occurred in these tests. Therefore, the values of the material parameters in Jordaan's model, obtained by $\mathrm{Xiao}^{23}$ are regarded as the reference in this study. There are differences in the parameter values between Xiao's paper and this study due to the difference in the numerical implementation method, model parameters, such as mesh size, and model dimensionality (a three-dimensional model instead of two-dimensional is applied in this paper).

Table 1 Material parameters used in the viscoelastic ice model

\begin{tabular}{ccc}
\hline Description & Parameter & Value \\
\hline Elastic modulus (elastic stiffness of Maxwell unit) & $E_{2}$ & $11800 \mathrm{MPa}$ \\
Viscosity coefficient of Maxwell unit & $\eta_{2}$ & $2.84 \times 10^{12} \mathrm{~Pa} \cdot \mathrm{s}$ \\
Elastic stiffness of Kelvin unit & $E_{1}$ & $8360 \mathrm{MPa}$ \\
Viscosity coefficient of Kelvin unit & $\eta_{1}$ & $6.75 \times 10^{10} \mathrm{~Pa} \cdot \mathrm{s}$ \\
Poisson's ratio & $v$ & 0.3 \\
Exponent parameter of Maxwell unit & & 1.1 \\
Damage parameter for elastic/shear modulus & & \\
Exponent parameters in damage function & $b$ & $15 \mathrm{MPa}$
\end{tabular}




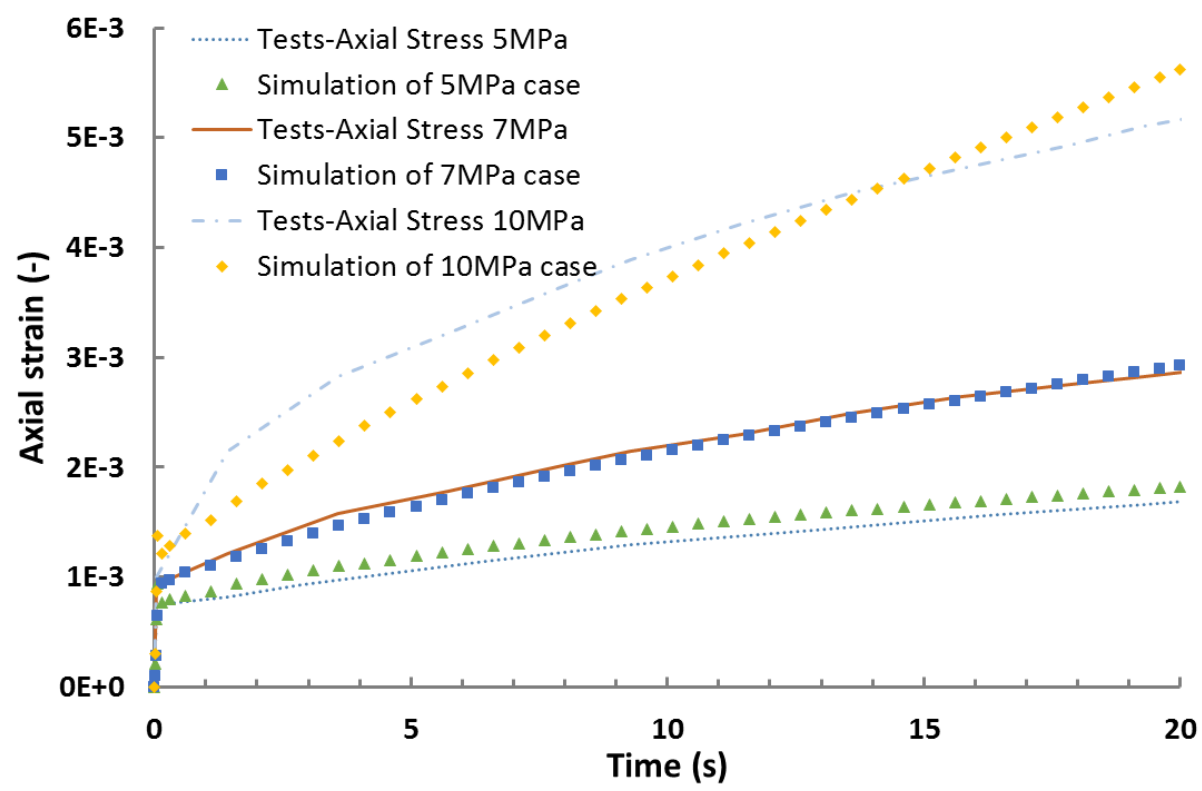

Figure 8 Comparisons of the simulation results and creep tests under different axial stresses (from 5

$\mathrm{MPa}$ to $10 \mathrm{MPa}$ ) and a confining pressure of $10 \mathrm{MPa}$.

The comparisons are shown in Figure 8. The simulated time-strain curves fit well with those of the experimental results. At the beginning of the curves, the axial strain increases rapidly, which reflects the elastic behaviour of the ice specimen. The ice model then exhibits viscous behaviour. For the $5 \mathrm{MPa}$ and $7 \mathrm{MPa}$ cases, the creep strain rate continues to decrease, which corresponds with the creep experiment. The decrease in the creep strain rate in the simulated curve is not as notable in the case of $10 \mathrm{MPa}$, possibly because the axial stress is large, and thus, the spring effect in Kelvin unit dominates the viscous behaviour of Burgers' model.

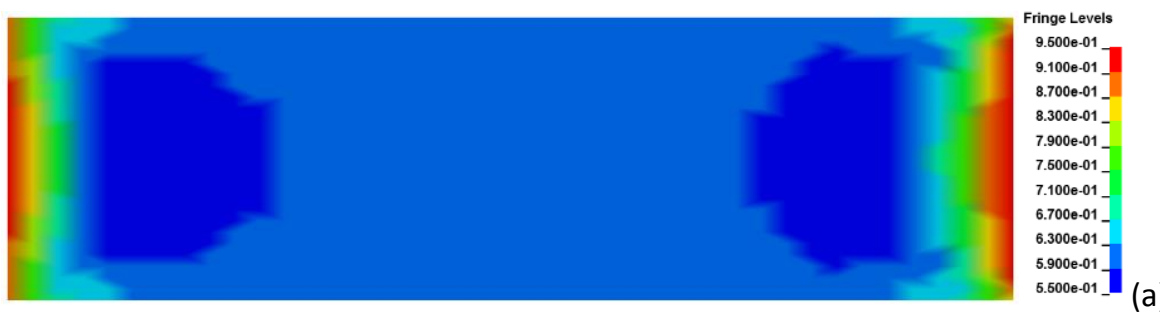



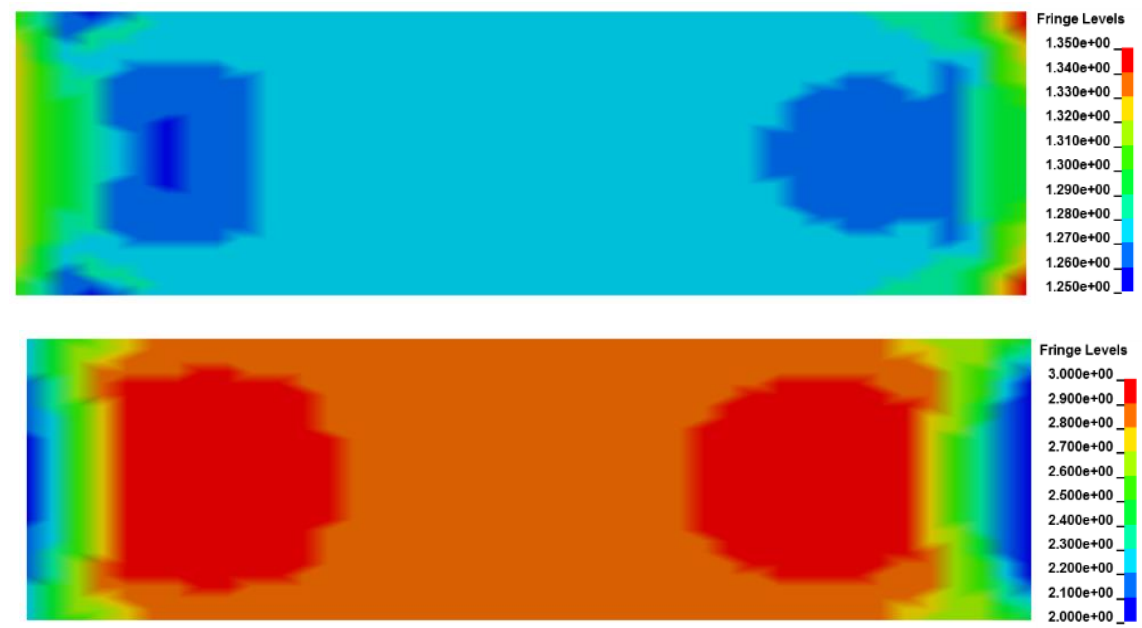

(b)

Figure 9 Damage contour plot of the inner section for different axial stress cases at time 20 s:

(a) $5 \mathrm{MPa}$, (b) $7 \mathrm{MPa}$, (c) $10 \mathrm{MPa}$ (unit of fringes is [s]).

The damage contour plots of the inner section at the ending time of the creep experiments are shown

in Figure 9. For the $5 \mathrm{MPa}$ and $7 \mathrm{MPa}$ cases, the damage increases rapidly at the boundary area and progresses slowly in the middle area (located between the boundary and the centre of the ice specimen). For the $10 \mathrm{MPa}$ case, the trend of the damage process is similar to those of the other two cases at the beginning of loading. Nevertheless, during the loading time, the damage grows rapidly in the middle area and slows down in the boundary area. This trend indicates that the axial stress affects the damage process in the ice specimen. In all three cases, a band approximately along the $45^{\circ}$ direction appears between the centre and middle area. This band is coincident with the simulation results conducted by $\mathrm{Li}^{36}$. The speed of the microstructure changes are different between the inside and outside of the band, which leads to inhomogeneity in the inner area of the ice. Localized strain instability mainly occurs along this band and causes the ice to fail. This type of failure has been widely observed in past triaxial tests of ice ${ }^{11,37}$. Because the bottom and top of the specimen are fixed, the damage difference between the boundary and middle area may be caused by boundary effects. 


\subsection{Constant strain rate experiments under triaxial stress conditions}

In this section, numerical simulations are conducted to compare the results with those obtained from the constant strain rate tests of cylinder iceberg specimen under triaxial stress conditions conducted by Gagnon and Gammon ${ }^{11}$. In their experiments, confining pressures were defined as 1.38 , 3.45 and 6.89 $\mathrm{MPa}$. With each confining pressure case, a series of constant strain rates, ranging from $4 \times 10^{-5}$ to $2 \times 10^{-1} \mathrm{~s}^{-1}$, were applied to the ice specimen. The boundary conditions are shown in Figure 10. Two types of failure modes, ductile and brittle, which were mainly influenced by the strain rate and confining pressure, were observed in the experiments. The ultimate stresses of each test and typical time-stress curves and time-strain curves of two failure modes were recorded in Gagnon and Gammon's paper ${ }^{11}$. The simulation model shown in Figure 11 has the same dimensions as the experimental specimen. The diameter and length of the cylindrical ice specimen are 95.8 and $260 \mathrm{~mm}$, respectively. Bottom of the simulation model is fixed, and the strain load is applied to the top of the ice specimen at a constant rate. Confining pressure is loaded on the cylindrical surface of the specimen. Convergence of element size is studied by comparing axial strain-stress curves for three element sizes, $16 \mathrm{~mm} \times 16 \mathrm{~mm} \times 7 \mathrm{~mm}, 8 \mathrm{~mm} \times 8 \mathrm{~mm} \times 3 \mathrm{~mm}$ and $4 \mathrm{~mm} \times 4 \mathrm{~mm} \times 1.5 \mathrm{~mm}$. The elastic behaviours of these three elements are highly similar, whereas in the viscous stage, the simulated stresses are different, and convergence occurs for the 8 and $4 \mathrm{~mm}$ elements. Size of $8 \mathrm{~mm} \times 8 \mathrm{~mm} \times 3 \mathrm{~mm}$, which is similar to the element size used in the prior section, is adopted. The material parameters shown in Table 1 are adopted in this section. Because the rate of the applied axial strain is larger than the transition rate and critical failure appears in the experiments, $f\left(\dot{\varepsilon}^{v}\right)$ and the failure criterion $S_{f}$ are activated in this section. The scale parameter $c$ in the expression of $f\left(\varepsilon^{v}\right)$ is set to 1.4. Based on trial-and-error 
simulations, the relation between $S_{f}$ and strain rate can be expressed as Equation (19), shown as the linear fitting line in Figure 12.

$$
S_{f}= \begin{cases}e^{2.67} \dot{\varepsilon}^{0.11} & \dot{\varepsilon}<3.3 \times 10^{-3} s^{-1} \\ e^{-5.25} \dot{\varepsilon}^{-1.28} & \dot{\varepsilon} \geq 3.3 \times 10^{-3} s^{-1}\end{cases}
$$

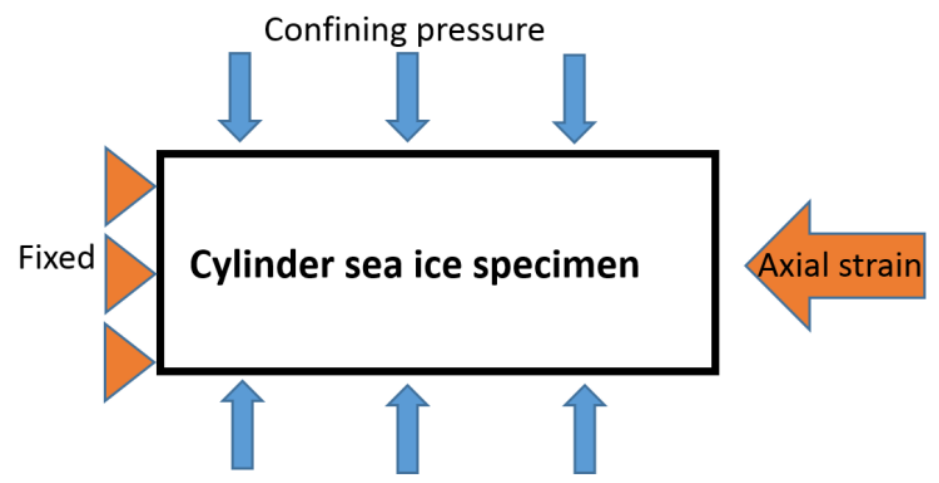

Figure 10 Schematic of the boundary condition in the constant strain rate experiments.

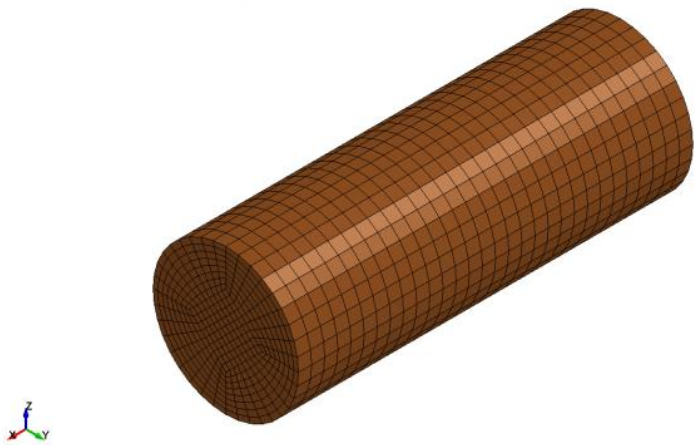

Figure 11 Simulation model of cylindrical ice with the same dimensions as the experimental ice sample. 


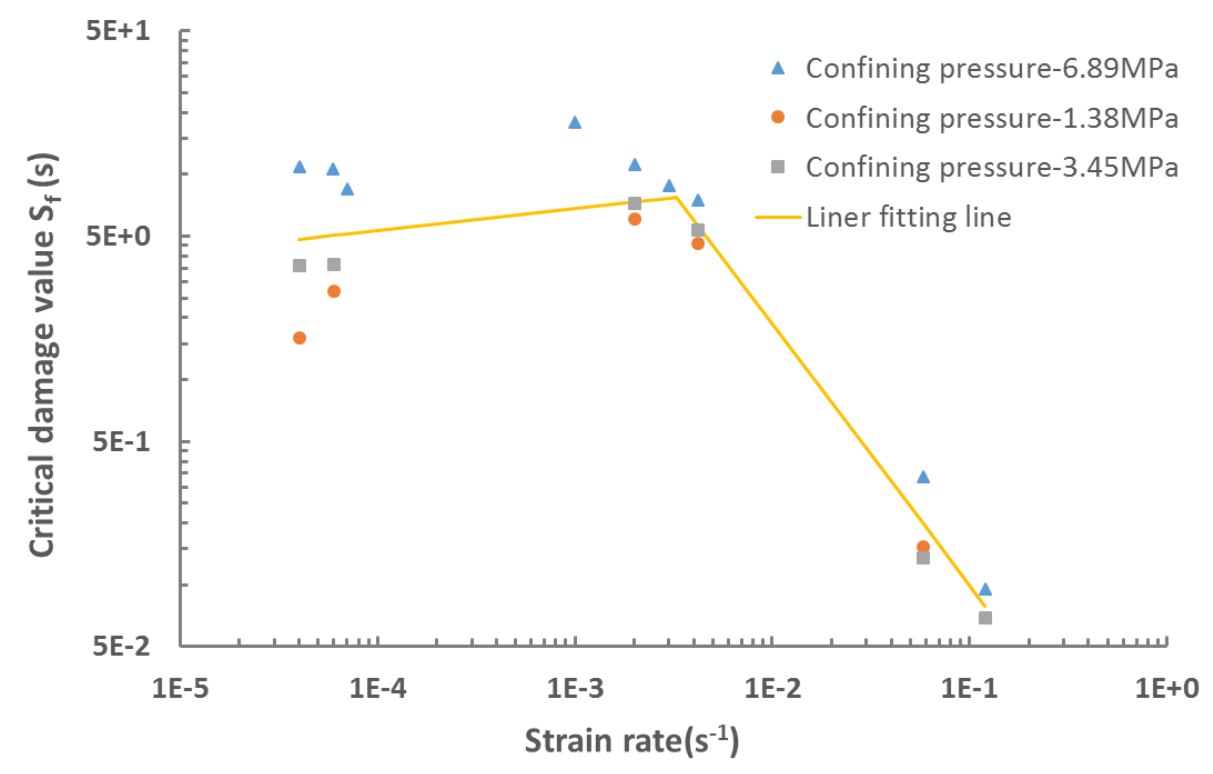

Figure 12 Relation between the critical damage value and strain rate under different confining pressures. The data are shown in $\log _{10}$ form.

Figure 12 illustrates that the value of critical damage fluctuates slightly before the transition rate and decreases rapidly upon reaching the transition rate. This trend corresponds to the physical basis of ice. When the strain rate is small, microcracks approximately distribute around the entire ice sample and have sufficient time to progress before large failure appears. At high strain rates, brittle fractures dominate the damage process and occur in a local area of the ice sample. The failure process is short, and the development of the damage is insufficient. Therefore, the critical damage value at high strain rates is considerably smaller than that at low strain rates. In Figure 12, high confining pressure clearly leads to a large critical damage value. This trend occurs because at high confining pressures, brittle fractures are suppressed, and microstructure changes, such as microcracks and recrystallization, are likely to occur. Nevertheless, the influence of the confining pressure on the critical damage is weak compared with the strain rate effects. 

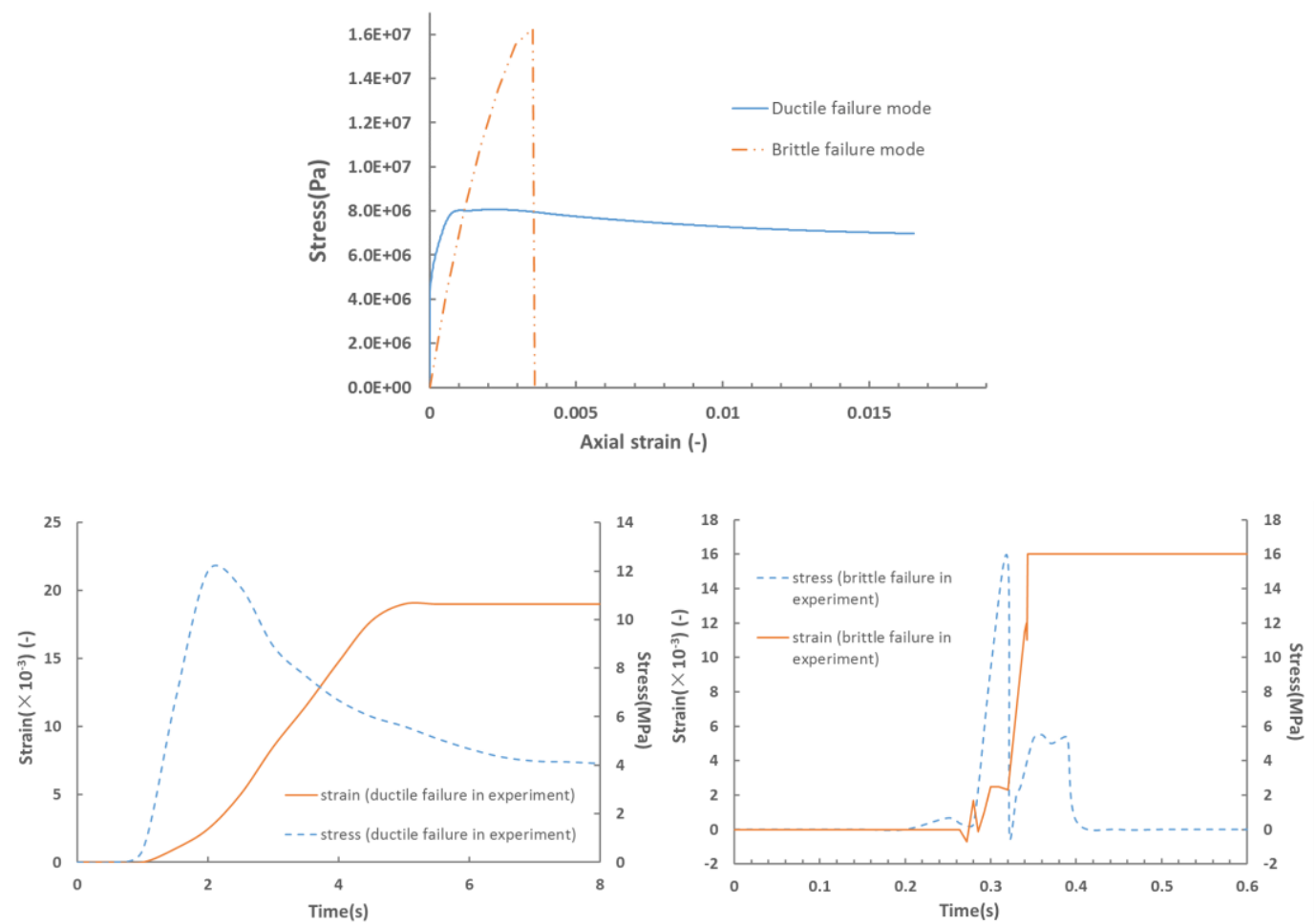

Figure 13 Top: simulated axial strain-stress curves; bottom: typical experimental results for the ductile and brittle failure modes.

For the ductile failure mode, the trend of the experimental strain-stress curve is captured by simulated results. As shown in Figure 13, the beginning of the simulated ductile curve shows elastic behaviour dominated by the spring in Maxwell unit. Then, Kelvin unit and the dashpot in Maxwell unit gradually regulate the behaviour of the ice specimen, and the slope decreases sharply at the transition point. The accumulation of damage in the viscous response represents the plastic failure process caused by extensive non-interacting microcracking in the experiments ${ }^{11}$. Therefore, the slope of the simulated curve decreases smoothly before the stress reaches a peak value. Then, the simulated stress decreases to a constant value, which is also observed in the experimental result.

As shown in Figure 13, for brittle failure, the sudden failure of ice after elastic behaviour is simulated well by the ice model. The slope of the simulated brittle curve is less than the ductile curve because the 
strain rate in brittle failure cases is greater than the transition rate, and the exponential constitutive relation of Burgers' model is adopted. Stress calculated from the exponential relation is considerably smaller than that from the linear relation. Similar to the damage contour plot shown in Figure 9(c), damage accumulates rapidly in the middle area of the numerical model. Ice elements of this area are first deleted when they reach the failure criterion, and the load capability of this model is lost abruptly. Continued slippage along the shear fracture plane after the initial abrupt decrease in stress was observed in the experiments. This leads to repeated accumulation and an abrupt decrease in stress in the time-stress curve. This phenomenon cannot be captured in this model because once a layer of the ice element is deleted, the ice model is separated into two parts, and the boundary condition can no longer constrain the model. The detailed simulation of the failure mode and regularly repeated load curve may be achieved by other numerical methods, such as the cohesive element method ${ }^{38}$.

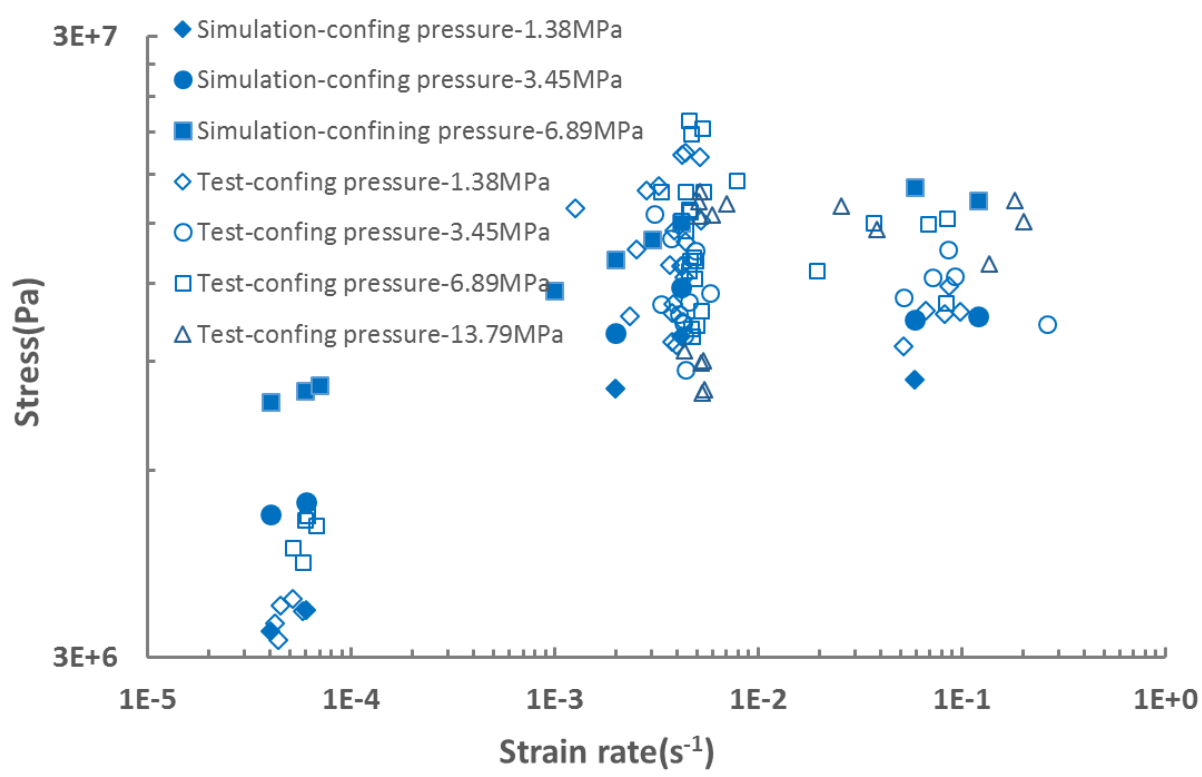

Figure 14 Comparison of the ultimate strength with different strain rates and confining pressures

between the simulated results and experimental results. The data are shown in $\log _{10}$ form.

The ultimate strength of the ice specimen under confining pressure is important when considering 
ship-iceberg collisions. The ultimate strengths from the simulations are compared with the experimental results as shown in Figure 14. The influence of the confining pressure and strain rate on the ultimate strength is reasonably reflected by the numerical ice model. At low strain rates, ice exhibits ductile behaviour, and microstructure changes dominate the failure mode. The influence of the confining pressure on the ultimate strength is obvious. Larger confining pressure leads to a higher ultimate strength. At the transition rate and at higher rates, the discreteness of ultimate strength is severe. The effects of the confining pressure are not apparent, possibly because at these strain rates, the ultimate value is dominated by brittle failure, which occurs somewhat at random and is influenced by the physical properties of the iceberg specimen, such as initial cracking and air bubbles. Because randomness is not considered in this numerical ice model, the influence of the confining pressure on the ultimate strength, in which higher confining pressure leads to higher ultimate strength, is apparent at all simulated strain rates. The calculated ultimate strengths correspond well with the experimental results at strain rates equal to and greater than the transition rate. When the strain rate is low, the calculated results of the confining pressure equal to $1.38 \mathrm{MPa}$ correspond well with the experimental results. Because the effect of the confining pressure is severe at low strain rates, the ultimate strengths at high confining pressures are considerably higher than in the experimental results, possibly because $f_{1}(p)$ in Equation (16) decreases considerably with increasing confining pressure. In each confining pressure case, the simulated ultimate strength increases exponentially with increasing strain rate when the strain rate is lower than the transition rate and remains fairly constant at strain rates higher than the transition rate. This trend coincides well with the trend of the experimental results. From the simulated data shown in Figure 14, the slope of the ultimate strength decreases with increasing confining pressure. Therefore, the confining pressure effects, reflected by Equation (16) in the ice model, 
play an important role in the simulation process, and the parameters in Equation (16) should be determined carefully.

\subsection{Collisions between an iceberg and a rigid steel plate}

In this section, collisions between a rigid steel plate and iceberg at the reality scale are simulated to investigate the features of the iceberg material model. Because the sphere shape can be regarded as the mean iceberg shape ${ }^{39}$, a spherical iceberg numerical model with a radius of $1 \mathrm{~m}$, as shown in Figure 15 , is established. Geometry of iceberg affects collision simulation results10, other typical geometry, such as cube, prism and cone should be studied in the future. Three element sizes, $20 \mathrm{~mm} \times 20 \mathrm{~mm} \times$ $20 \mathrm{~mm}, 30 \mathrm{~mm} \times 30 \mathrm{~mm} \times 30 \mathrm{~mm}$ and $40 \mathrm{~mm} \times 40 \mathrm{~mm} \times 40 \mathrm{~mm}$, are analysed, and the simulated displacement-contact force curves are compared. The largest element yields a $15 \%$ smaller contact force than the other two elements, and convergence occurs for the $20 \mathrm{~mm}$ and $30 \mathrm{~mm}$ element sizes. Therefore, the $30 \mathrm{~mm} \times 30 \mathrm{~mm} \times 30 \mathrm{~mm}$ element size is adopted. To reduce the calculation time, the upper hemisphere, which will not impact the steel plate, is set as the rigid material. The material parameters of the iceberg ice are the same as given in Table 1. The density of the iceberg is set to 900 $\mathrm{kg} / \mathrm{m}^{3}$. The static and dynamic friction coefficients are both set to 0.15 . The upper hemisphere is fixed in all directions, and a constant velocity in the z-direction is applied to the steel plate. Contact between new surfaces, generated from ice element erosion, is considered.

According to the iceberg collision experiments and bergy bit accidents ${ }^{3,40,41}$, three impact speeds, covering the entire range of these speeds $-0.1,1$ and $10 \mathrm{~m} / \mathrm{s}-$ are simulated in this section. Based on trial and error simulations, a uniform failure criterion, $S_{f}=1.18 \times 10^{-4} \mathrm{~s}$, is adopted for these three cases. The trial numerical simulation shows that the confining pressure in the iceberg-steel plate collision is 
approximately $4 \mathrm{MPa}$, which coincides with the stress condition in the previous section. Therefore, the scale parameter is set to the same as that in the last section.

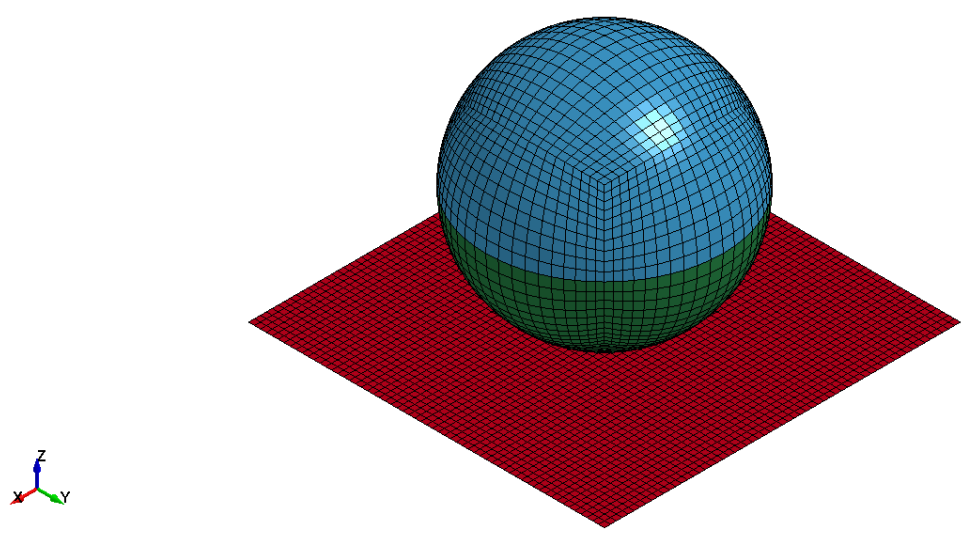

Figure 15 Illustration of a collision between a spherical iceberg and rigid steel plate

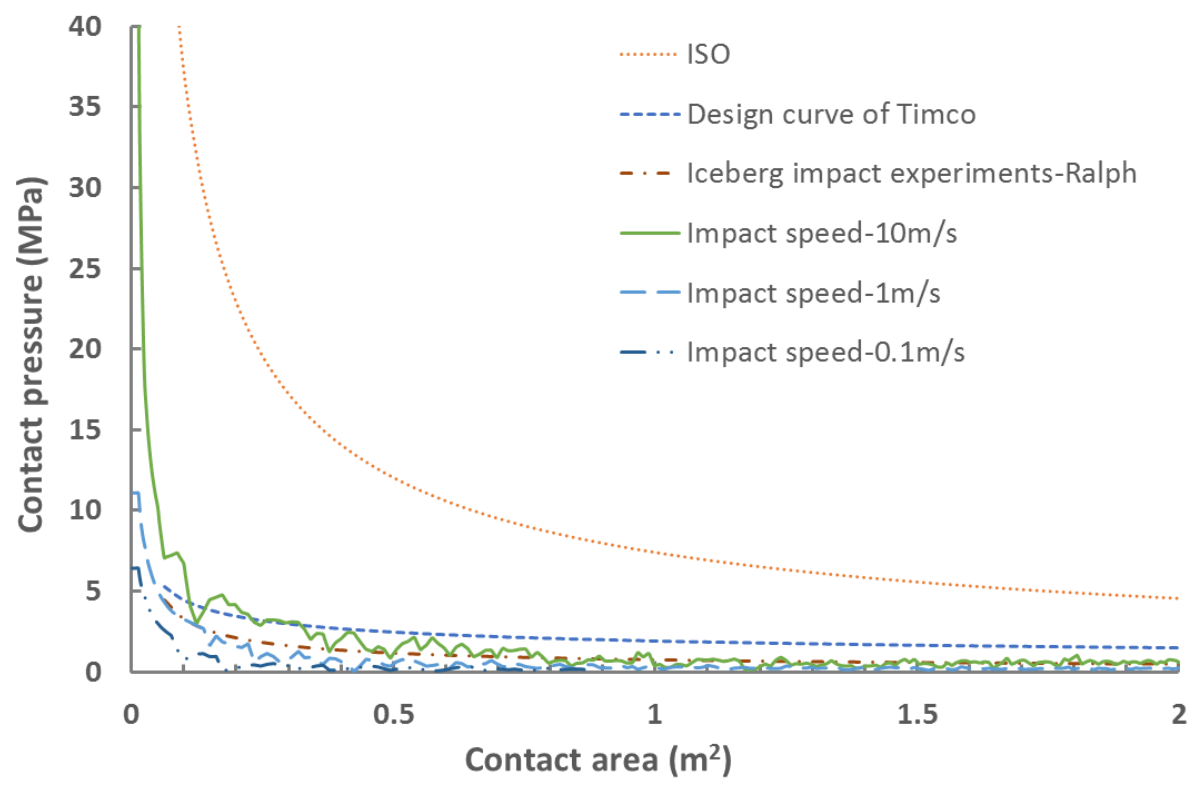

Figure 16 Comparison of the contact area-contact pressure curves between the simulated cases at different impact speeds and design codes.

Area-pressure curves are widely applied to the determination of ice loads in the design process of 
marine structures and ships. Simulated area-pressure curves at different impact speeds are compared with those obtained from the design codes and the experimental results and are shown in Figure 16. The simulated results show that the contact pressure decreases rapidly at the beginning of impact and smoothly reaches a constant value with increases in the contact area. This trend coincides well with the design codes and experimental curves. All simulation results are smaller than the $\mathrm{ISO}^{42}$ design curve, which is reasonable because the design codes should be conservative to some extent. In addition, the design curve considers all types of ice loads, such as ice sheet collisions and large ice floe impacts, which may generate considerably larger impact forces on structures than small bergy bits. The calculated curves fit well with the results of iceberg impact experiments conducted by Ralph et al. $^{3}$ and the design curve proposed by Timco ${ }^{43}$. Pressure fluctuations are observed in the simulated curves due to erosion process of ice elements. The growth rate of the maximum pressure increases with increasing impact speed because at high speed, elastic behaviour dominates the response of the iceberg, and the contact force increases more rapidly than in collisions at low speed, as shown in Figure 17.

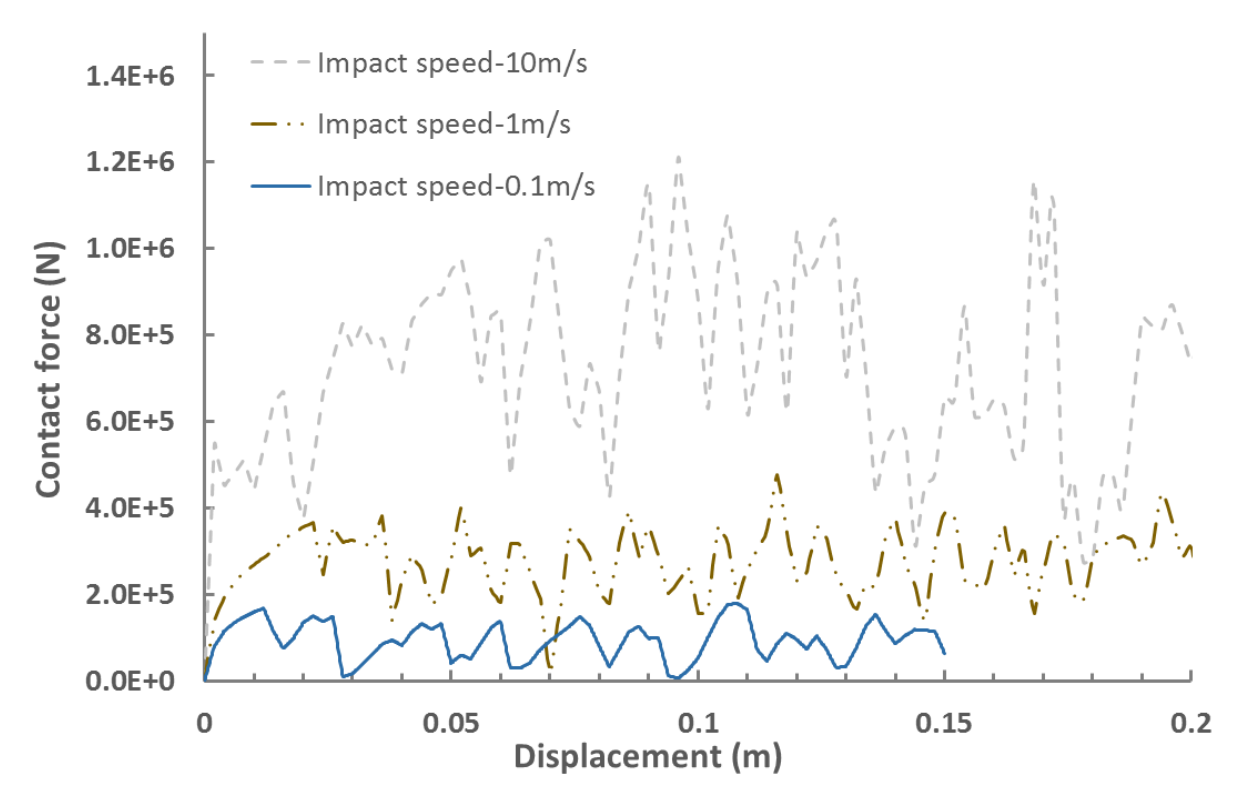

Figure 17 Simulated relations between penetration and contact force at different impact speeds. 
The characteristics of fluctuations in the contact force (often called sawtooth) and the influence of the contact speed on ice failure modes and response types are shown in Figure 17. At a relatively low collision speed, ductile behaviour dominates the iceberg response. Before reaching the repeated peak force, the contact force increases slowly, during which the microstructure damage accumulates, and the slope of the curve decreases, as discussed in the previous section. Upon reaching the peak value, the residual strength of the ice is still large, as shown in Figure 13. Therefore, the decreasing rate of the contact force is slow. For the moderate speed case, the iceberg exhibits ductile behaviour at the beginning of contact. Then, ice elements at the contact surface exhibit elastic behaviour and are regularly deleted layer by layer as the contact penetration increases. The frequency of loading/unloading is rather constant, approximately $85 \mathrm{~Hz}$, which is typically observed at the icestructure interaction. This shows the great potential of applying this model to study the coupled behaviour in ice-flexible structure interaction, particularly in the simulation of 'lock-in' behaviour, which will be conducted in the future. At high speeds, the elastic component in the Burgers model plays an important role; the contact force increased rapidly and linearly. Damage rapidly accumulates not only in the contact layer but also inside the iceberg. Therefore, failure appears rather randomly on and inside the contact surface.

It should be noted that erosion process significantly affect fluctuations and magnitude of contact force curves and area-pressure curves. Proper failure criteria is important for this simulation. Figure 12 shows the influence of one important factor, strain rate, on failure criteria. There are also other impact factors, such as element size and iceberg geometry. These factors should be carefully considered when deciding failure criteria. 


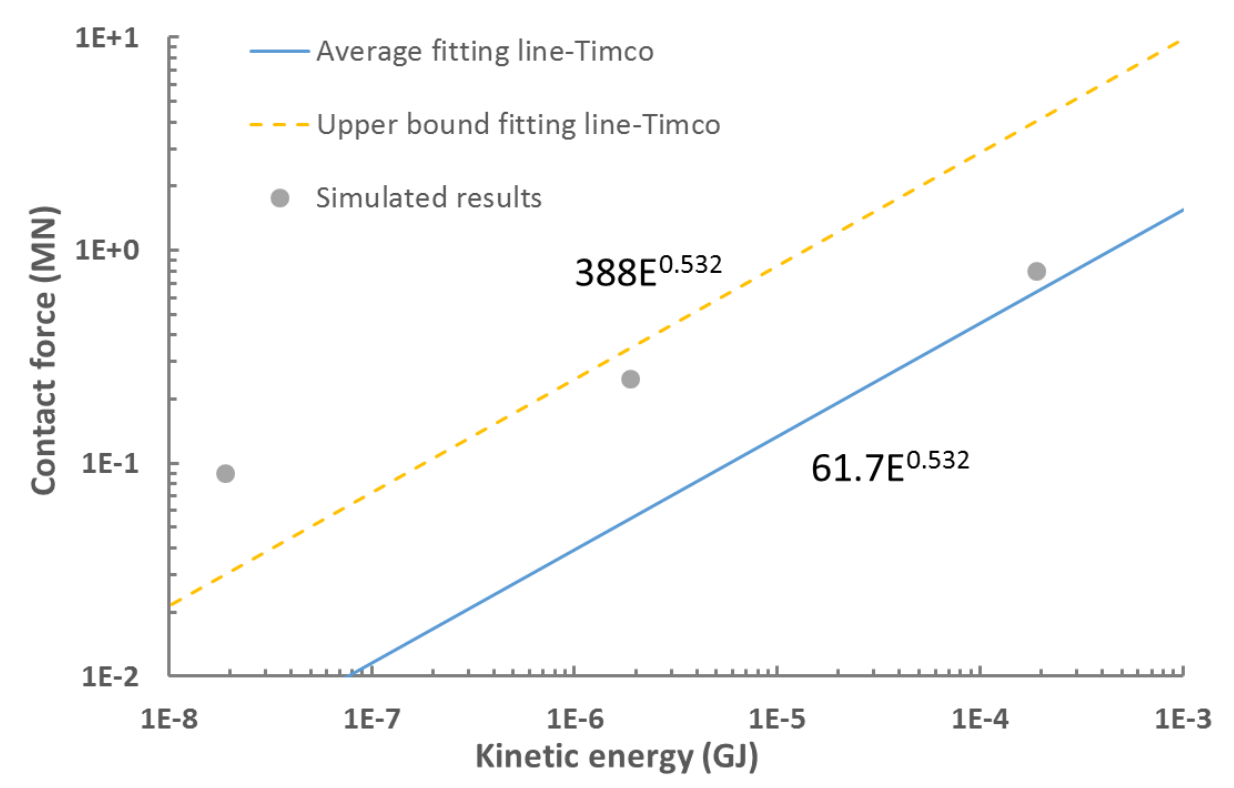

Figure 18 Relation between the kinetic energy and contact force. The data are shown in $\log _{10}$

form.

Investigating the relation between the kinetic energy of the iceberg and contact force is another viewpoint to estimate the impact force in ship-iceberg collisions. Timco ${ }^{41}$ summarized all available data related to ice floe impacts on structures and fitted them, as shown in Figure 18. The upper bound covers $95 \%$ of the selected data. The simulated contact force at $10 \mathrm{~m} / \mathrm{s}$ and $1 \mathrm{~m} / \mathrm{s}$ is located in the data range, whereas at $0.1 \mathrm{~m} / \mathrm{s}$, the contact force is greater than the recorded data. This result occurs because in the range of simulated kinetic energy, a decrease in the kinetic energy of the recorded experiments is caused by a decrease in ice floe mass, whereas the contact speed maintains a constant range, from 1 $\mathrm{m} / \mathrm{s}$ to $2 \mathrm{~m} / \mathrm{s}$. Therefore, an impacted ice floe may show brittle failure, which yields a smaller contact force than ductile failure in the simulation case at $0.1 \mathrm{~m} / \mathrm{s}$. The comparison in Figure 18 shows that the iceberg material model accurately simulates the contact force at moderate speeds, $1 \mathrm{~m} / \mathrm{s}$ to $10 \mathrm{~m} / \mathrm{s}$, which commonly occurs in real ship/marine structure-iceberg collisions. For low-speed contact, this model may lead to high contact force and should be adopted with caution. 


\section{Conclusions}

A new iceberg material model is proposed and validated by simulating two typical mechanical experiments of ice and one iceberg-steel plate collision at the reality scale. The most important results are as follows:

(1) A nonlinear viscoelastic iceberg material model considering strain rate effects and failure criteria is proposed based on the model of Jordaan et al. ${ }^{27}$. Exponential expressions of Maxwell unit and Kelvin unit cause the stress of the iceberg model to remain fairly constant upon the transition rate. The damage function and failure criteria can reasonably describe the accumulation of microstructural changes and large fracture failures in ice.

(2) Time-strain curves and damage distribution plots in creep experiments are reasonably simulated.

The simulation process shows that axial stress affects the damage process in ice specimens.

(3) The simulated ultimate strengths in constant strain rate experiments fit well with the experimental results, illustrating that this iceberg model can accurately illustrate the influence of the strain rate and confining pressure on ice behaviour. Strain-stress curves of two typical failure modes, brittle failure and ductile failure, are reasonably simulated by the iceberg model.

(4) In iceberg-rigid steel plate collisions, area-pressure curves and relations of kinetic energy and contact force at engineering interested speeds fit well with the experimental results. The influence of the impact speed on contact force-penetration curves is captured. The constant frequency of loading/unloading in the contact force-penetration curve is roughly simulated by this model.

In addition, the iceberg material model can be used to study iceberg-flexible structure interactions incorporating iceberg-structure interactions. 


\section{Acknowledgements}

The work contained in this paper is part of a joint-research project between the State Key Laboratory of

Ocean Engineering at Shanghai Jiao Tong University and the Department of Shipping and Marine Technology at Chalmers University of Technology. This support is greatly appreciated by the authors.

\section{Reference}

1.Hill B. Ship collision with iceberg database. In: $7^{\text {th }}$ International Conference and Exhibition on Performance of Ships and Structures in Ice. Alberta, Canada, 16-19 July, 2006.

2.Ralph F, McKenna R, Gagnon R. Iceberg characterization for the bergy bit impact study. Cold Reg Sci Technol. 2008; 52: 7-28.

3.Ralph F, McKenna R, Crocker G, Croasdale K. Pressure/Area measurements from the grappling island iceberg impact experiment. In: $17^{\text {th }}$ IAHR International Symposium on Ice. St Petersburg, Russia, 2125 June, 2004; 171-178.

4.Johnston M, Ritch R, Gagnon R. Comparison of impact forces measured by different instrumentation systems on the CCGS Terry Fox during the Bergy Bit Trials. Cold Reg Sci Technol. 2008; 52: 83-97.

5.Gagnon R, Cumming D, Ritch R, et al. Overview of bergy bit impact trials. In: $16^{\text {th }}$ IAHR International Symposium on Ice. Dunedin, New Zealand, 2nd-6th December, 2002; 458-65.

6.Frederking RMW, Hausler F-U. The flexural behaviour of ice from in situ cantilever beam tests. In: $4^{\text {th }}$ IAHR Symposium on Ice Problems. Lulea, Sweden, 7-9 August, 1978; vol. 1, pp.197-215.

7.Iliescu D, Schulson EM. The brittle compressive failure of fresh-water columnar ice loaded biaxially. Acta Mater. 2004; 52: 5723-35. 
8.Polach RvB, Ehlers S. Model scale ice-Part B: Numerical model. Cold Reg Sci Technol. 2013; 94: 53-

60.

9.Timco G, Weeks W. A review of the engineering properties of sea ice. Cold Reg Sci Technol. 2010; 60: 107-29.

10.Liu Z, Amdahl J, Løset S. Plasticity based material modelling of ice and its application to ship-iceberg impacts. Cold Reg Sci Technol. 2011; 65: 326-34.

11.Gagnon R, Gammon P. Triaxial experiments on iceberg and glacier ice. J Glacio. 1995; 41: 528-40.

12.Gagnon R, Gammon P. Characterization and flexural strength of iceberg and glacier ice. J Glacio. 1995 41: 103-11.

13.Jones SJ, Gagnon R, Derradji A, Bugden A. Compressive strength of iceberg ice. Can J Phys. 2003; 81: 191-200.

14. Muggeridge K, Jordaan I. Microstructural change in ice: III Observations from an iceberg impact zone. J Glacio. 1999; 45: 449-55.

15.Polach RvB, Ehlers S. On the Scalability of Model-Scale Ice Experiments. In: ASME 2014 33rd International Conference on Ocean, Offshore and Arctic Engineering. San Francisco, USA, 8-13 June, 2014; p. V010T07A-VT07A.

16.Das J, Ehlers S. Numerical Simulation of Crushing and Bending Failure of Ice Using SPH. In: ASME 2015 34th International Conference on Ocean, Offshore and Arctic Engineering. St. John's, Canada, May 31-June 5, 2015; p. V008T07A19-VT07A19.

17.Shunying J, Shao-cheng D, Zheng L, Xiang-jun B. Discrete element modelling of interaction between sea ice and vertical offshore structures. Engineering Mechanics. 2013; 30: 463-9.

18.Gagnon R. A numerical model of ice crushing using a foam analogue. Cold Reg Sci Technol. 2011; 65: 
335-50.

19.Gagnon R, Wang J. Numerical simulations of a tanker collision with a bergy bit incorporating hydrodynamics, a validated ice model and damage to the vessel. Cold Reg Sci Technol. 2012; 81: 26 35.

20.Derradji-Aouat A. Multi-surface failure criterion for saline ice in the brittle regime. Cold Reg Sci Technol. 2003; 36: 47-70.

21.Derradji-Aouat A, Sinha NK, Evgin E. Mathematical modelling of monotonic and cyclic behaviour of fresh water columnar grained S-2 ice. Cold Reg Sci Technol. 2000; 31: 59-81.

22.Schapery R. Models for the deformation behavior of viscoelastic media with distributed damage and their applicability to ice. In Jones S et al. (eds) Ice-Structure Interaction: Springer, 1991, p. 191-230.

23.Xiao J. Damage and fracture of brittle viscoelastic solids with application to ice load models. PhD thesis, Memorial University of Newfoundland, Canada, 1997.

24.Jordaan IJ, Matskevitch DG, Meglis IL. Disintegration of ice under fast compressive loading. Int J Fract. 1999; 97: 279-300.

25.Ehlers S. A particle swarm optimization-based procedure to obtain a crashworthy ice-classed LNG tanker. In: $6^{T H}$ International conference on Collision and Grounding of Ships and Offshore Structures. Trondheim, Norway, 17-19 June, 2013; 233-240.

26.Ehlers S, Kujala P. Optimization-based material parameter identification for the numerical simulation of sea ice in four-point bending. Proc Inst Mech Eng M J Eng Marit Environ. 2013: 228 (1) 70-80.

27.Jordaan I, McKenna R, Duthinh D, et al. Development of new ice load models. Report for Canada Oil and Gas Lands Administration (COGLA) by C-CORE, Memorial University, St John's, NF. 1990: 206. 28.Sinha NK. Rheology of columnar-grained ice. Exp Mech. 1978; 18: 464-70. 
29. Michel B, Toussaint N. Mechanisms and theory of indentation of ice plates. J Glacio. 1977; 19: 285300.

30. Harper B. A uniaxial nonlinear viscoelastic constitutive relation for ice. J Energy Res Technol. 1986; 108: $156-60$.

31.Singh SK. Mechanical behaviour of viscoelastic material with changing microstructure. PhD thesis, Memorial University of Newfoundland, Canada, 1993.

32. Kachanov M. Elastic solids with many cracks and related problems. Advances in applied mechanics. 1993; 30: 259-445.

33. Hallquist JO. LS-DYNA theory manual. Livermore software Technology corporation. 2006; 3: 25-31.

34.Chen S-j, Guo W-j, Zhou H, Shen B, Liu J-b. Field investigation of long-term bearing capacity of strip coal pillars. Int J Rock Mech Min Sci. 2014; 70: 109-14.

35.Kristensen VB. Visco-elastic response of thermoplastics. Master thesis, Norwegian University of Science and Technology, Norway, 2013.

36.Li C. Finite element analysis of ice-structure interaction with a viscoelastic model coupled with damage mechanics. PhD thesis, Memorial University of Newfoundland, Canada, 2002.

37. Barrette P, Jordaan I. Compressive Behaviour Of Confined Polycrystalline Ice. Report for The National Research Council Program on Energy Research and Development (PERD), Memorial University, St John's, NF. Decemeber, 2001: 4-77.

38.Kuutti J, Kolari K, Marjavaara P. Simulation of ice crushing experiments with cohesive surface methodology. Cold Reg Sci Technol. 2013; 92: 17-28.

39.McKenna R. Iceberg shape characterization. In: 18th International Conference on Port and Ocean Engineering under Arctic Conditions. Potsdam, USA, June 26-30 2005, p. 555-64. 
40.Bruneau SE, Cammaert A, Croasdale K. Field tests for iceberg impact loading. In: $12^{\text {th }} I A H R$ International Symposium on Ice. Trondheim, Norway, August 23-26, 1994; p. 23-6.

41.Timco G. Isolated ice floe impacts. Cold Reg Sci Technol. 2011; 68: 35-48.

42. Masterson D, Frederking R, Wright B, Kärnä T, Maddock W. A revised ice pressure-area curve. In: $19^{\text {th }}$ International Conference on Port and Ocean Engineering under Arctic Conditions. Dalian, China, June 27-30, 2007, p. 305-14.

43.Timco G, Sudom D. Revisiting the Sanderson pressure-area curve: Defining parameters that influence ice pressure. Cold Reg Sci Technol. 2013; 95: 53-66.

\section{APPENDIX}

The details of the numerical implementation of the viscoelastic ice model established in this paper are discussed here.

The total strain increment $\Delta \varepsilon_{i}$ (equal to the sum of elastic strain and creep strain) at time $t+\Delta t$ is obtained from the main program. The developed program is used to update the stress state, creep strain and elastic strain at moment $t+\Delta t$.

First, the influence of the strain rate on the nonlinear Maxwell unit and Kelvin unit is calculated. For the multi-axial stress state, the viscous strain rate in Equation (10) is substituted by an equivalent strain increment shown in Equation (20).

$$
\frac{\overline{\Delta \varepsilon}}{d t}=\frac{\sqrt{\frac{2}{3} d \varepsilon_{i j} d \varepsilon_{i j}}}{d t}
$$

Second, pseudo time is calculated by solving Equation (11). In the following calculation, time $t$ represents pseudo time. $\bar{\varepsilon}^{c(t)}$ and $\bar{\sigma}^{(t)}$ are the equivalent creep strain and equivalent stress at time $t$, respectively. They are defined below. 


$$
\begin{aligned}
& \bar{\varepsilon}^{c(t)}=\sqrt{\frac{2}{3} \varepsilon_{i j}^{c(t)} \varepsilon_{i j}^{c(t)}} \\
& \bar{\sigma}^{(t)}=\sqrt{\frac{3}{2} s_{i j}^{(t)} s_{i j}^{(t)}}
\end{aligned}
$$

Third, Equation set (23) is solved by the iterative method. The tress strain and creep strain increment are then updated. The first equation shows that the increment of creep strain is proportional to the deviatoric stress. By substituting it into the second equation, the stress strain in moment $t+\Delta t$ can be obtained, as shown in Equation (24). With the new stress strain, the increment of creep strain can be updated based on the first equation in formula set (23). If the difference between the new creep strain increment (obtained in step $\mathrm{k}+1$ ) and the old creep strain increment (obtained in step k) is smaller than the criterion, the calculation is finished. Otherwise, a new calculation step $k+2$ should be performed.

$$
\left\{\begin{array}{l}
\Delta \varepsilon_{i j(k+1)}^{c}=\frac{3}{2} \frac{\dot{\varepsilon}_{(k)}^{c(t+\theta \Delta t)} \Delta t}{\bar{\sigma}_{(k)}^{(t+\theta \Delta t)}} S_{i j(k+1)}^{(t+\theta \Delta t)} \\
\Delta \sigma_{(k+1)}=D_{i j}^{(t)}\left(\Delta \varepsilon_{i j}-\Delta \varepsilon_{i j(k+1)}^{c}\right)+\left(D_{i j}^{(t+\Delta t)}-D_{i j}^{(t)}\right) \varepsilon_{i j}^{e(t)}
\end{array}\right.
$$

where, $\theta$ is constant parameter located between 0 and 1. $\theta=0.5$ is adopted in our model. $D_{i j}$ is elastic modulus. $\varepsilon_{i j}^{e(t)}$ is elastic strain in time $t$.

$$
B_{i j}^{(t+\theta \Delta t)} \sigma_{i j(k+1)}^{(t+\Delta t)}=D_{i j}^{(\mathrm{t})} \Delta \varepsilon_{j}+A_{i j}^{(t+\theta \Delta t)} \sigma_{i j}^{(t)}+\left(D_{i j}^{(t+\Delta t)}-D_{i j}^{(t)}\right) \varepsilon_{i j}^{e(t)}
$$

where,

$$
\begin{aligned}
& B_{i j}^{(t+\theta \Delta t)}=\overline{\mathbf{1}}+\theta \Delta t \frac{3}{2} \frac{\dot{\varepsilon}_{(k)}^{c(t+\theta \Delta t)} \Delta t}{\bar{\sigma}_{(k)}^{(t+\theta \Delta t)}} D_{i j}^{(t)}\left(\overline{\mathbf{1}}-\frac{1}{3} m m^{T}\right) \\
& A_{i j}^{(t+\theta \Delta t)}=\overline{\mathbf{1}}-(1-\theta) \Delta t \frac{3}{2} \frac{\dot{\varepsilon}_{(k)}^{c(t+\theta \Delta t)} \Delta t}{\bar{\sigma}_{(k)}^{(t+\theta \Delta t)}} D_{i j}^{(t)}\left(\overline{\mathbf{1}}-\frac{1}{3} m m^{T}\right) \\
& m^{T}=\left[\begin{array}{llllll}
1 & 1 & 1 & 0 & 0 & 0
\end{array}\right]
\end{aligned}
$$

